\title{
CATÁLOGO DE OBJETOS CERÁMICOS \\ EN LA BODEGA DE PALENQUE, CHIAPAS
}

\author{
Patricia FournIER G. \\ Fernando López Aguilar \\ ENAH \\ Ma. de Lourdes FournIER G.
}

UAM

\section{Introducción}

El Instituto Nacional de Antropología e Historia, a través de la Dirección de Monumentos Prehispánicos, emprendió una fase de exploraciones en el sitio arqueológico de Palenque, Chiapas, en relación con el programa de Parques Nacionales de la Secretaría de Desarrollo Urbano y Ecología. De esta manera, en 1981 se inició un proyecto arqueológico y en la temporada 1982 los responsables del proyecto fueron Fernando López Aguilar y Rosalva Nieto Calleja. Estuvo a cargo del análisis de materiales Patricia Fournier García, todos bajo la dirección de Roberto García Moll.

Las intenciones del proyecto eran la conservación del sitio y el sentar las bases para continuar las investigaciones arqueológicas en Palenque, estudios que incluían la catalogación de materiales depositados en la bodega de la zona como complemento al trabajo de Schele y Mathews (1979), además de una amplia revisión bibliográfica sobre las intervenciones previamente realizadas en el sitio.

Las primeras noticias que se tienen de Palenque en la época contemporánea datan de 1773 , cuando Ramón Ordóñez y Aguiar hizo exploraciones y descripciones del sitio. A partir de 1784 , año en que José Antonio Calderón realizó un reconocimiento de las ruinas, numerosos viajeros, exploradores, historiadores, arquitectos y arqueológos efectuaron estudios y excavaciones con la finalidad de entender aspectos del contexto histórico social del sitio. Entre ellos se distinguieron el capitán 
Antonio del Río (1786), Guillermo Dupaix (1807), el conde Frederick Waldeck (1832), John L. Stephens y Frederick Catherwood (1840), Desiré Charnay $(1858,1872)$, Alfred P. Maudslay (1890), William Holmes (1897 cf. Blom 1923: 14), Frans Blom (1923), Miguel Ángel Fernández (19341945), Alberto Ruz Lhuillier (1949-1958), Jorge R. Acosta (1967-1976) y César A. Sáenz (1977 a la fecha).

En términos particulares, el objetivo de la arqueología es reconstruir la historia de sitios como Palenque en el momento en que estuvieron ocupados y funcionaron como unidades sociales. Ahora bien, la historia de un sitio también incluye los procesos naturales y culturales que alteran las evidencias materiales de sociedades pasadas, que son vestigios observables en el presente. De ahí que conocer las intervenciones efectuadas con anterioridad por investigadores, llámense arqueólogos o no, permite comprender en parte la alteración del contexto arqueológico para así remitirse a su estado original a partir de las características actuales.

A pesar de que exista la idea generalizada de que el arqueólogo busca tesoros de gran valor en términos monetarios, los materiales que le permiten reconstruir la historia de los sitios normalmente consisten en objetos desechados (salvo en los casos de ofrendas y enterramientos) que sí tienen valor, pero como documento histórico y como patrimonio cultural. Estos hallazgos deben ordenarse y clasificarse para así poder manejarlos en la reconstrucción histórica, señalando similitudes y diferencias a través del tiempo en que funcionó una sociedad determinada, establecida en un sitio.

Para sociedades agrícolas y sedentarias el material arqueológico más representado es la cerámica, dada su funcionalidad en el ámbito cotidiano y ceremonial, además de su corta vida como objeto útil. La cerámica es un indicador cronológico sensible, puesto que en cualquier cultura hay dinamismo estilístico. Comúnmente el trabajo del arqueólogo abarca el análisis clasificatorio no sólo de piezas completas, sino también de fragmentos, o sea tiestos, que son más fácilmente ordenables remitiéndose a vasijas en donde pueden observarse todas las características o atributos.

En el caso de Palenque, hasta que se emprendió el trabajo que aquí se publica, el análisis de piezas completas había sido parcial y la presentación de resultados se encontraba dispersa 
en diferentes artículos, además de que el análisis de los tiestos no era totalmente claro.

\section{El catálogo}

Este catálogo de materiales arqueológicos almacenados en la bodega del sitio de Palenque, Chiapas, se inició con la finalidad de obtener un muestrario de tipos cerámicos, ya que de esta manera se posibilitaría un fácil manejo de los materiales que se llegasen a recuperar en futuras excavaciones y reconocimientos de superficie. Sin embargo, al inventariarse los contenidos de 18 cajas depositadas por R. L, Rands en 1976 en la bodega de Palenque, se constató que se trataba de materiales procedentes de diferentes sitios de la región palencana. A pesar de que de 1951 a 1976 el citado investigador exportó a E.U.A. un gran volumen de materiales de Palenque y sitios aledaños, en muchos casos con carácter devolutivo, sólo tenemos noticias del envío a México en 1967 de un muestrario sumamente reducido (Archivo Técnico de Monumentos Prehispánicos, $8 / 311.42 \mathrm{R} / 21-2$ ) y suponemos que el resto continúa en el extranjero, sin que sea factible llevar a cabo una revisión de la tipología, además de que se desconoce con exactitud en qué sectores del sitio se realizaron exploraciones arqueológicas y excavaciones estratigráficas con el objeto de establecer la secuencia cerámica local.

Debido a lo anteriormente expuesto, se decidió catalogar los objetos cerámicos que se encuentran en la bodega, ya que Schele y Mathews (1979) enfocaron su trabajo principalmente a estucos e inscripciones, siendo mínima la atención prestada a la cerámica.

Para el ordenamiento de los objetos cerámicos catalogados se asignó un número arbitrario a cada uno de ellos y se tomaron en consideración una serie de datos como: procedencia (incluyendo los números del catálogo realizado por Schele y Mathews), presentando para su fácil referencia el plano de la Zona Arqueológica de Palenque, tomado de Ruz (1978); forma (forma genérica, descripción de partes y dimensiones); pasta (anotando textura, desgrasante y color, especificado cuando fue posible mediante la clave Munsell correspondiente), acabado de la superficie y decoración; complejos y observaciones pertinentes. Cabe señalar que un complejo está constituido por 
toda la cerámica relacionada con una cultura en una región o sitio, durante una época específica (Smith y Gifford: 1965); en consecuencia, un complejo no es directamente observable en los materiales arqueológicos aislados, sino que se infiere a través de sus asociaciones contextuales.

Se contempló como un elemento importante en este catálogo un apartado correspondiente a complejo; no obstante, al revisar los artículos referentes a la cerámica de Palenque (Rands $1965,1967,1969,1973,1974 a, 1974 b$; Rands y Rands 1957) se encontró que no fueron considerados en el análisis algunos objetos cuya cronología es relativamente fácil de determinar por asociaciones en ofrendas y con monumentos fechados; cabe mencionar que hasta el momento no existe una publicación completa sobre la cerámica de Palenque, como señalamos en la Introducción, ni han sido establecidos los tipos cerámicos.

Ya que en el catálogo se hará referencia a los diferentes complejos a los cuales corresponden los objetos, se presenta a continuación la secuencia cerámica de Palenque:

\begin{tabular}{lr}
\hline Balunté Tardío & $810-850$ d.C. \\
Balunté Temprano & $770-810$ d.C. \\
Murciélagos & $790-770$ d.C. \\
Otolum Tardío & $650-690$ d.C. \\
Otolum Temprano & $600-650$ d.C. \\
Motiepa & (?) $400-600$ d.C. \\
Picota & (?) $200-400$ d.C. \\
Manifestaciones Preclásicas & (?) a.C. -100 d.C. \\
Sin nombre &
\end{tabular}

Esta secuencia fue provista por Rands y Bishop (1975: 125) y en la medida en que no se ha elaborado otra, se retoma para la presente catalogación.

Cabe cuestionarse si la secuencia cerámica de un sitio puede establecerse sin haber delimitado su extensión, definido las características generales del asentamiento y, obviamente, sin excavaciones estratigráficas en aquellos sectores que representen la variabilidad ocupacional del sitio y, en consecuencia, la cerámica. 


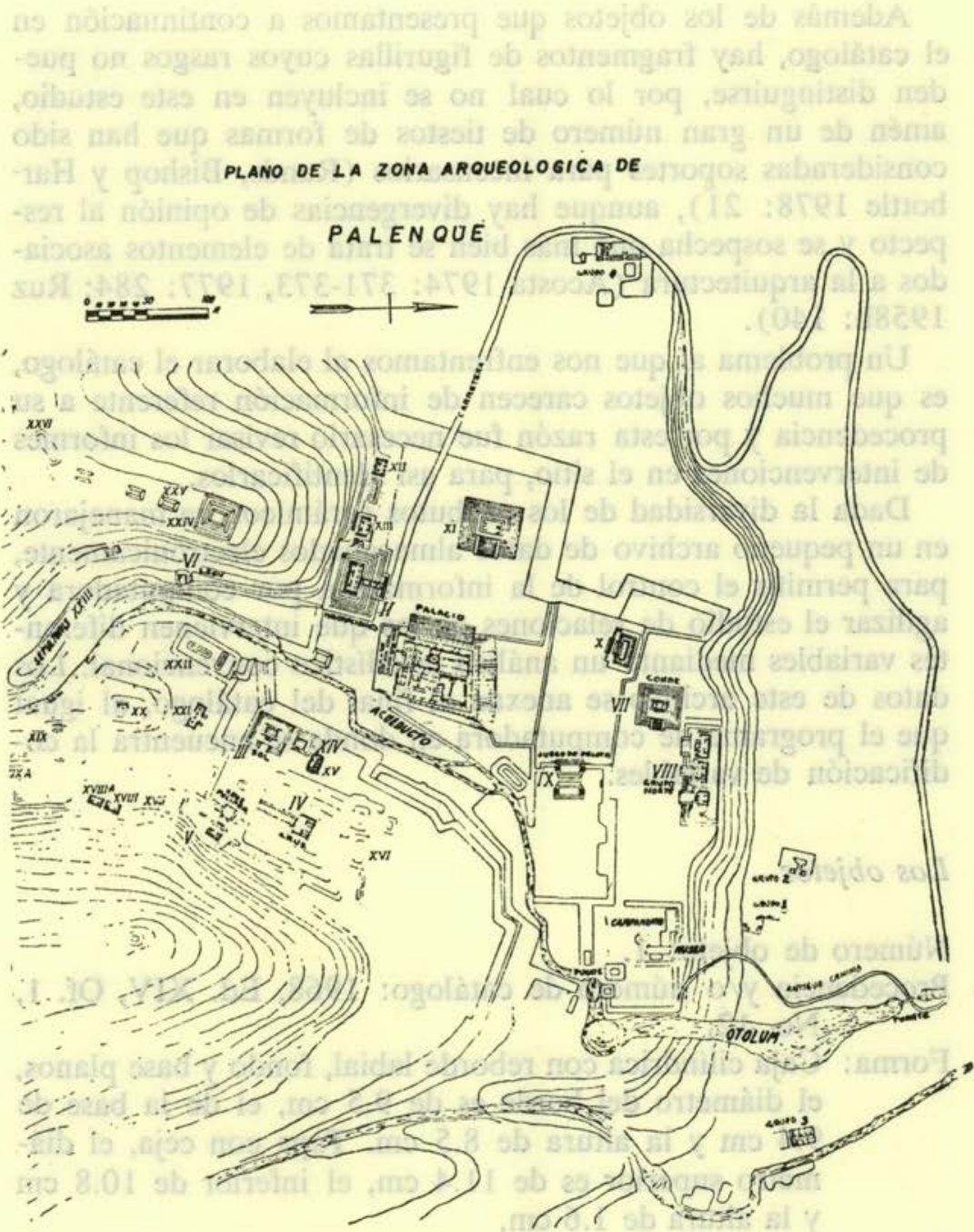

Mapa 1. Plano arqueológico de la zona de Palenque. 
Además de los objetos que presentamos a continuación en el catálogo, hay fragmentos de figurillas cuyos rasgos no pueden distinguirse, por lo cual no se incluyen en este estudio, amén de un gran número de tiestos de formas que han sido consideradas soportes para incensarios (Rands, Bishop y Harbottle 1978: 21), aunque hay divergencias de opinión al respecto y se sospecha que más bien se trata de elementos asociados a la arquitectura (Acosta 1974: 371-373, 1977: 284; Ruz 1958b: 140).

Un problema al que nos enfrentamos al elaborar el catálogo, es que muchos objetos carecen de información referente a su procedencia y por esta razón fue necesario revisar los informes de intervenciones en el sitio, para así identificarlos.

Dada la diversidad de los atributos cerámicos, se manejaron en un pequeño archivo de datos almacenados electrónicamente, para permitir el control de la información por computadora y agilizar el estudio de relaciones en las que intervienen diferentes variables mediante un análisis estadístíco convencional. Los datos de este archivo se anexan al final del catálogo, al igual que el programa de computadora en donde se encuentra la codificación de variables.

\section{Los objetos}

Número de objeto: 1 .

Procedencia y/o número de catálogo: 1968, Ed. XIV, Of. 1, No. 12.

Forma: Caja cilíndrica con reborde labial, fondo y base planos, el diámetro del borde es de $9.5 \mathrm{~cm}$, el de la base de $9.4 \mathrm{~cm}$ y la altura de $8.5 \mathrm{~cm}$. Tapa con ceja, el diámetro superior es de $11.4 \mathrm{~cm}$, el inferior de $10.8 \mathrm{~cm}$ y la altura de $1.6 \mathrm{~cm}$.

Pasta: Pasta de textura media, con desgrasante de cuarzo, color rojizo.

Acabado de la superficie y decoración: Las superficies están alisadas, en el interior hay restos de engobe rojizo.

Complejo: En el análisis realizado por Rands sobre los materiales de Palenque, nunca considera esta clase de objetos. Son comunes las cajas cilíndricas con tapa como ofrendas, en muchos casos conteniendo huese- 


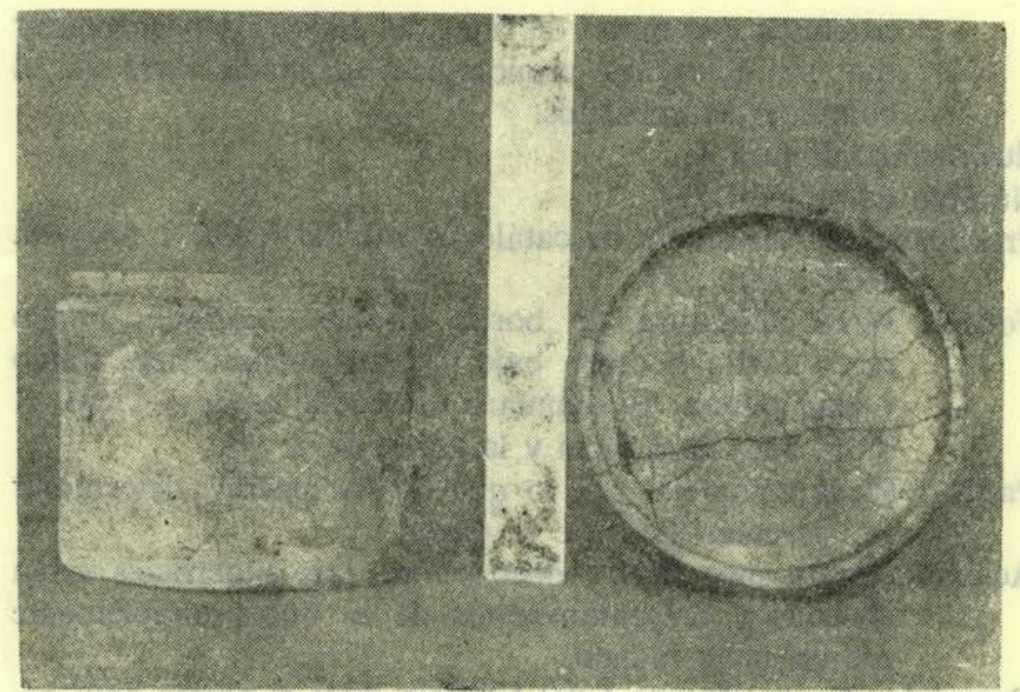

Figura 1 Objek 1

cillos de aves o monos, e incluso falanges de jaguar. Se recuperaron en el Templo de la Cruz, lado oriente, ofrendas 5, 6 y 7 (Fernández 1943: 10), además de la ofrenda II (Ruz 1953: 8); en el Templo de la Cruz Foliada en una ofrenda en los techos (Sáenz 1979: 26-28); en el Templo del Sol, ofrendas 1 y 2 (Fernández 1942: 2); en el Templo V del Grupo Norte, ofrenda 1 (Ruz 1958a: 5); en el Templo XVIII-A (Ruz 1958a: 12); en una ofrenda en la sección suroeste del Palacio (Sáenz 1979: 27); en la ofrenda 1 del edificio XIV (Acosta 1973: 33-35). El Templo de la Cruz está fechado en 690 d.C.; el de la Cruz Foliada en 692 d.C.; es probable que el Templo XIV sea contemporáneo a las dos estructuras anteriores, aun cuando el tablero carece de serie inicial y la serie secundaria está incompleta, por lo cual no puede determinarse la fecha, sin embargo bajo el piso de estuco se encontraron dos braceros cilíndricos (Acosta 1977: 283-284), los cuales probablemente corresponden a los complejos Murciélagos y Balunté (Rands 1969: 46; Rands, Bishop y Harbottle 1978: 23). La aparición de cajas cilíndricas con tapa en es- 
tructuras que datan de fines del siglo VII hace pensar que su ubicación cronológica adecuada sería en el complejo Murciélagos.

Ilustración: Figura 1.

Número de Objeto: 2.

Procedencia y/o número de catálogo: Ed. XIV, Of. 1 (Acosta 1973: Fig. 37).

Forma: Jarra miniatura de borde directo cuadrado, cuello recto corto, hombro bajo, cuerpo semiesférico, fondo y base planos. El diámetro del borde es de $4.1 \mathrm{~cm}$, el de la base de $2.6 \mathrm{~cm}$ y la altura de $8 \mathrm{~cm}$.

Pasta: Pieza completa, por lo que no fue posible determinar las características de la pasta.

Acabado de la superficie y decoración: Las superficies están alisadas y presentan restos de lo que probablemente fue un baño blanco.

Complejo: En la ofrenda I del Edificio XIV el objeto aquí catalogado está asociado a una caja cilíndrica con tapa (Acosta 1973: 33-35), por lo cual correspondería al Complejo Murciélagos (véase el apartado correspondiente a Complejo en la cédula del Objeto 1).

Ilustración: Figura 2.

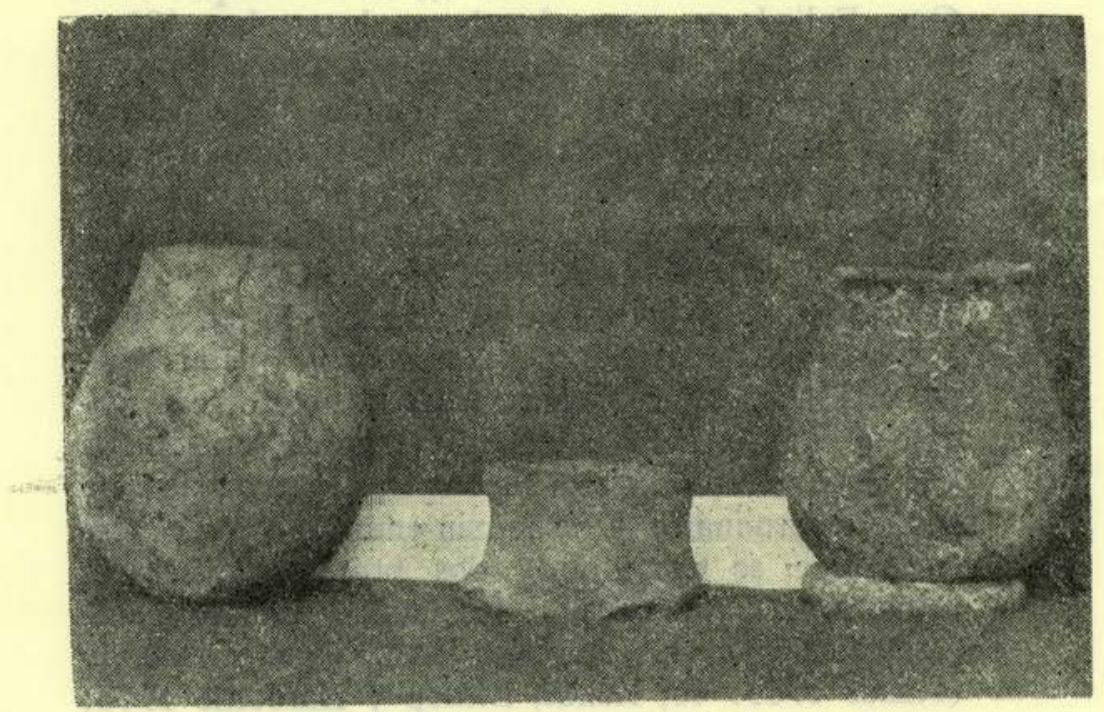

Figura 2. Objetos 2, 3 y 4 
Número de Objeto: 3 .

Procedencia y/o número de catálogo: Cat. 1061-A.

Forma: Cajete miniatura con borde directo cuadrado con cuerpo recto con curvatura externa, fondo plano, base cóncava y reborde basal. El diámetro del borde es de $4.5 \mathrm{~cm}$, el de la base de $5.4 \mathrm{~cm}$ y la altura de $3 \mathrm{~cm}$.

Pasta: Pieza completa, por lo que no fue posible determinar las características de la pasta.

Acabado de la superficie y decoración: Las superficies están alisadas y cubiertas con un baño blanco.

Complejo: Probablemente Balunté.

Observaciones: En la ofrenda 4 del Grupo II se encontró un objeto con forma semejante al aquí catalogado (Zavala 1949: Fig. 169a) asociado a vasijas correspondientes al Clásico Tardío, probablemente del Grupo Chablekal (Ibid: Fig. 155a, 156a) característico en Palenque del Complejo Balunté (Rands 1973: 191).

Ilustración: Figura 2.

Número de Objeto: 4.

Procedencia y/o número de catálogo: 1956, Norte V Of. 1-4; Cat. 1054 B.

Forma: Jarra miniatura con borde semievertido con biselado interno, cuello cóncavo corto, hombro bajo poco pronunciado, fondo plano, soporte anular. El diámetro del borde es de $4.8 \mathrm{~cm}$, el de la base de $5 \mathrm{~cm}$ y la altura de $7.5 \mathrm{~cm}$.

Pasta: Pasta de textura media, con desgrasante de cuarzo.

Acabado de la superficie y decoración: Las superficies están alisadas, aparentemente sin engobe, apreciándose manchas de cocción.

Complejo: En la ofrenda I del Templo V del Grupo Norte el objeto aquí catalogado está asociado a una caja cilíndrica con tapa (Ruz 1958a: 5), por lo cual correspondería al Complejo Murciélagos (véase el apartado correspondiente a Complejo en la cédula del Objeto 1 ).

Ilustración: Figura 2. 


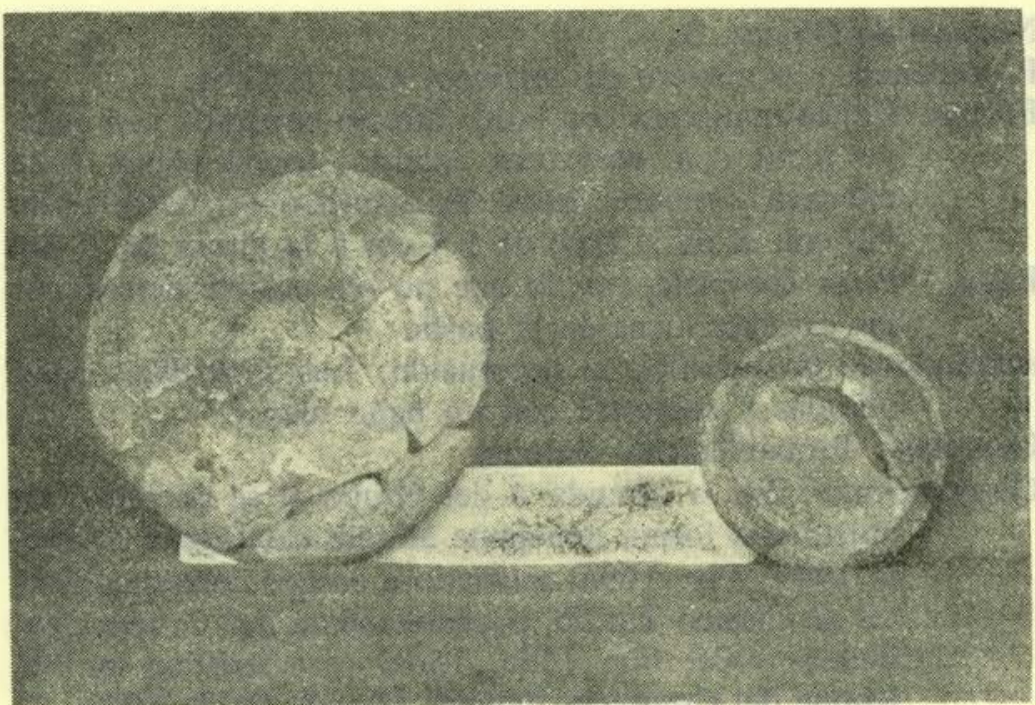

Figura 3. Objetos 5 y 7

Número de Objeto: 5.

Procedencia y/o número de catálogo: 1956, Norte V, Of. 1-3; Cat. 1053 A.

Forma: Plato miniatura con borde redondo ligeramente evertido, paredes rectas con curvatura externa, fondo con concavidad central, base plana. El diámetro del borde es de $8.8 \mathrm{~cm}$, el de la base de $3.6 \mathrm{~cm}$ y la altura de $1.8 \mathrm{~cm}$.

Pasta: Pasta de textura media con desgrasante de arena de cuarzo, color amarillo rojizo $(7.5$ YR $7 / 6)$ con núcleo ancho gris oscuro (2.5 YR 4/0).

Acabado de la superficie y decoración: Las superficies están alisadas y cubiertas con un baño blanco.

Complejo: En la ofrenda I del Templo V del grupo Norte el objeto aquí catalogado está asociado a cajas que cronológicamente hemos ubicado en el complejo Murciélagos (ver el apartado correspondiente a Complejo en la cédula del Objeto 1 ).

Observaciones: Hay otro objeto con esta misma forma que presenta engobe rojo, también de la Ofrenda I (Obj. 6) del Templo V del Grupo Norte (Cat. 517).

Ilustración: Figura 3. 
Número de Objeto: 7.

Procedencia y/o número de catálogo: Probablemente Grupo Norte, Templo V, Ofrenda III (Ruz 1958a: Fig. j).

Forma: Plato miniatura (probablemente tapa) con borde directo cuadrado, cuerpo semiesférico, fondo ligeramente cóncavo y base plana. El diámetro del borde es de $5.4 \mathrm{~cm}$, el de la base de $4.2 \mathrm{~cm}$ y la altura $1.6 \mathrm{~cm}$.

Pasta: Pasta de textura burda con desgrasante de cuarzo.

Acabado de la superficie y decoración: Las superficies están alisadas y probablemente están cubiertas con un baño blanco, sumamente erosionado; en el fondo hay restos de cinabrio.

Complejo: Posiblemente Murciélagos.

Observaciones: En la Tumba I del Templo XVIII-A una pieza similar está asociada a una figurilla (Ruz 1958a: 10) que corresponde estilísticamente al Clásico Tardío; en la ofrenda I del Templo de la Cruz (c. 690 d.C.) hay un plato miniatura, colocado a manera de tapa (Ruz 1953: Fig. 4b), cuya forma se asemeja al objeto aquí catalogado.

Ilustración: Figura 3.

Número de Objeto: 8.

Procedencia y/o número de catálogo: 1956, Norte V, Of. 1-5.

Cat. $517 \mathrm{~A}$.

Forma: Cajete de borde directo cuadrado, paredes semiesféricas, fondo convexo y base cóncava. El diámetro del borde es de $10 \mathrm{~cm}$, el de la base de $4.7 \mathrm{~cm}$ y la altura de $4.4 \mathrm{~cm}$.

Pasta: Pieza completa, restaurada, por lo que no fue posible determinar las características de la pasta.

Acabado de la superficie y decoración: Las superficies están alisadas y cubiertas con un engobe blanco, sumamente erosionado. Según Ruz (1958a: Fig. 9e) este objeto presenta restos de pintura negra, sin embargo al analizar la pieza no se apreciaron evidencias de dicho color.

Complejo: En la ofrenda I del Templo V del Grupo Norte el objeto aquí catalogado está asociado a una caja cilíndrica con tapa (Ruz 1958a: 5), por lo cual corres- 
pondería al Complejo Murciélagos (véase el apartado correspondiente a Complejo en la cédula del Objeto 1$)$.

Ilustración: Figura 5.

Número de Objeto: 9.

Procedencia y/o número de catálogo: 1956, Norte V, Of. 1-2, Cat. 1053 B.

Forma: Cajete de paredes curvas convergentes, fondo convexo y base cóncava. El diámetro estimado del borde es de $10 \mathrm{~cm}$, el de la base $6 \mathrm{~cm}$ y la altura $7.5 \mathrm{~cm}$.

Pasta: Pasta de textura fina, con desgrasante de cuarzo, pasta roja $(2.5$ YR 4/6) con núcleo delgado café oscuro (7.5 YR 4/4).

Acabado de la superficie y decoración: Las superficies están alisadas y cubiertas con un engobe blanco. Según Ruz (1958: Fig. 9b) este objeto presenta pintura negativa crema, sin embargo al analizar la pieza no se apreció ningún motivo decorativo al negativo.

Complejo: En la ofrenda I del Templo V del Grupo Norte, el objeto aquí catalogado está asociado a una caja ci-

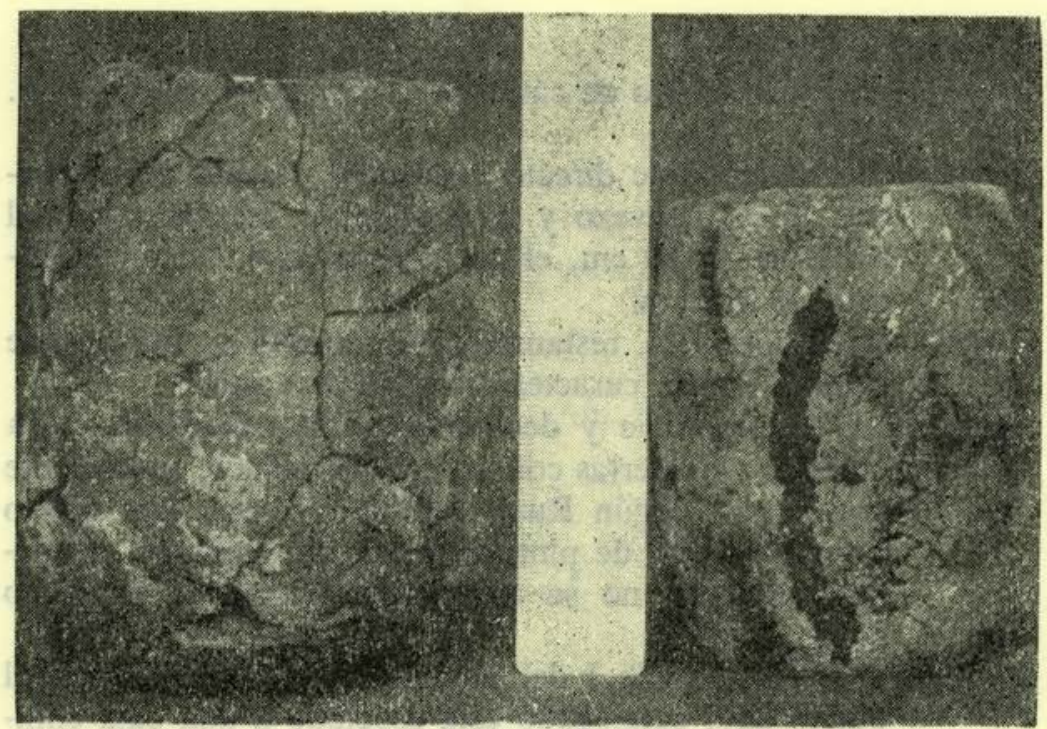

Figura 4 , Objetos 10 y 11 
líndrica con tapa (Ruz 1958a: 5), por lo cual correspondería al Complejo Murciélagos (véase el apartado correspondiente a Complejo en la cédula del Objeto 1).

Ilustración: Figura 5.

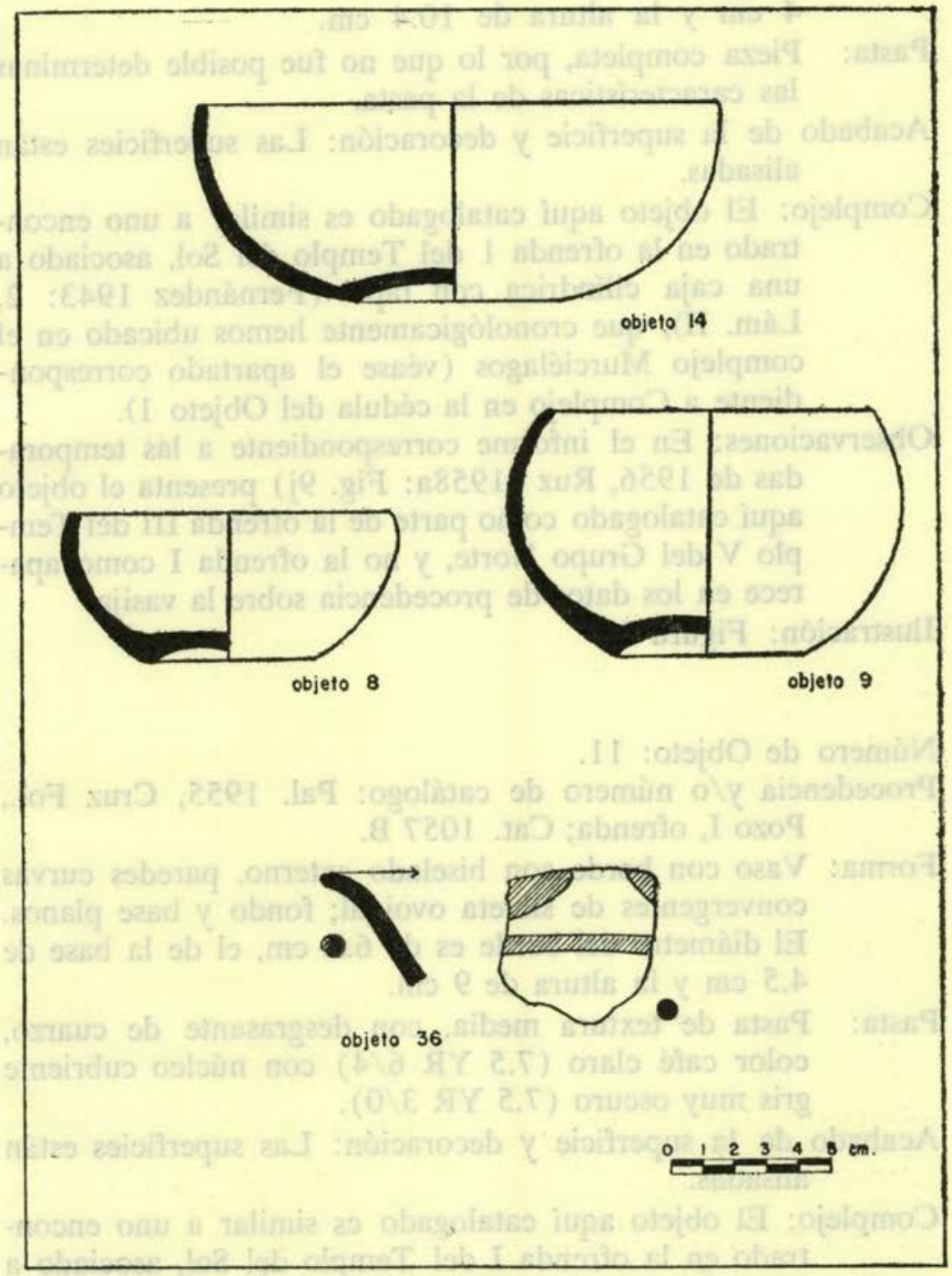

Figura 5 
Número de Objeto: 10.

Procedencia y/o número de catálogo: Pal. 1956, Norte V, Of. 1-2; Cat. $105 \mathrm{~A}$.

Forma: Vaso con borde con biselado externo, paredes curvas convergentes de silueta ovoidal, fondo y base planos. El diámetro del borde es de $6.5 \mathrm{~cm}$, el de la base de $4 \mathrm{~cm}$ y la altura de $10.4 \mathrm{~cm}$.

Pasta: Pieza completa, por lo que no fue posible determinar las características de la pasta.

Acabado de la superficie y decoración: Las superficies están alisadas.

Complejo: El objeto aquí catalogado es similar a uno encontrado en la ofrenda 1 del Templo del Sol, asociado a una caja cilíndrica con tapa (Fernández 1943: 2, Lám. II), que cronológicamente hemos ubicado en el complejo Murciélagos (véase el apartado correspondiente a Complejo en la cédula del Objeto 1).

Observaciones: En el informe correspondiente a las temporadas de 1956, Ruz (1958a: Fig. 9j) presenta el objeto aquí catalogado como parte de la ofrenda III del Templo V del Grupo Norte, y no la ofrenda I como aparece en los datos de procedencia sobre la vasija.

Ilustración: Figura 4.

Número de Objeto: 11.

Procedencia y/o número de catálogo: Pal. 1955, Cruz Fol., Pozo I, ofrenda; Cat. 1057 B.

Forma: Vaso con borde con biselado externo, paredes curvas convergentes de silueta ovoidal; fondo y base planos. El diámetro del borde es de $6.2 \mathrm{~cm}$, el de la base de $4.5 \mathrm{~cm}$ y la altura de $9 \mathrm{~cm}$.

Pasta: Pasta de textura media, con desgrasante de cuarzo, color café claro (7.5 YR 6/4) con núcleo cubriente gris muy oscuro (7.5 YR 3/0).

Acabado de la superficie y decoración: Las superficies están alisadas.

Complejo: El objeto aquí catalogado es similar a uno encontrado en la ofrenda I del Templo del Sol, asociado a una caja cilíndrica con tapa (Fernández 1943: 2, Lám. 
II) que cronológicamente hemos ubicado en el Complejo Murciélagos (véase el apartado correspondiente a Complejo en la cédula del Objeto 1 ).

Ilustración: Figura 4.

Número de Objeto: 12.

Procedencia y/o número de catálogo: Montículo Funerario I, Entierro 3 (Acosta 1975: Fig. 47, 2; Hernández 1972: $1,5)$.

Forma: Cajete de borde redondo, cuello corto, cuerpo semiesférico, fondo ligeramente convexo y base cóncava. El diámetro del borde es de $12.3 \mathrm{~cm}$, el de la base de $6 \mathrm{~cm}$ y la altura de $9 \mathrm{~cm}$.

Pasta: Pasta de textura fina, con desgrasante de cuarzo, color rojo $(2.5$ YR $5 / 6)$.

Acabado de la superficie y decoración: Las superficies están alisadas y el cuello está decorado con una banda color rojo.

Complejo: En el Entierro 3 del Montículo Funerario I el objeto aquí catalogado está asociado a un plato trípode cuya forma es semejante a los de la ofrenda en la

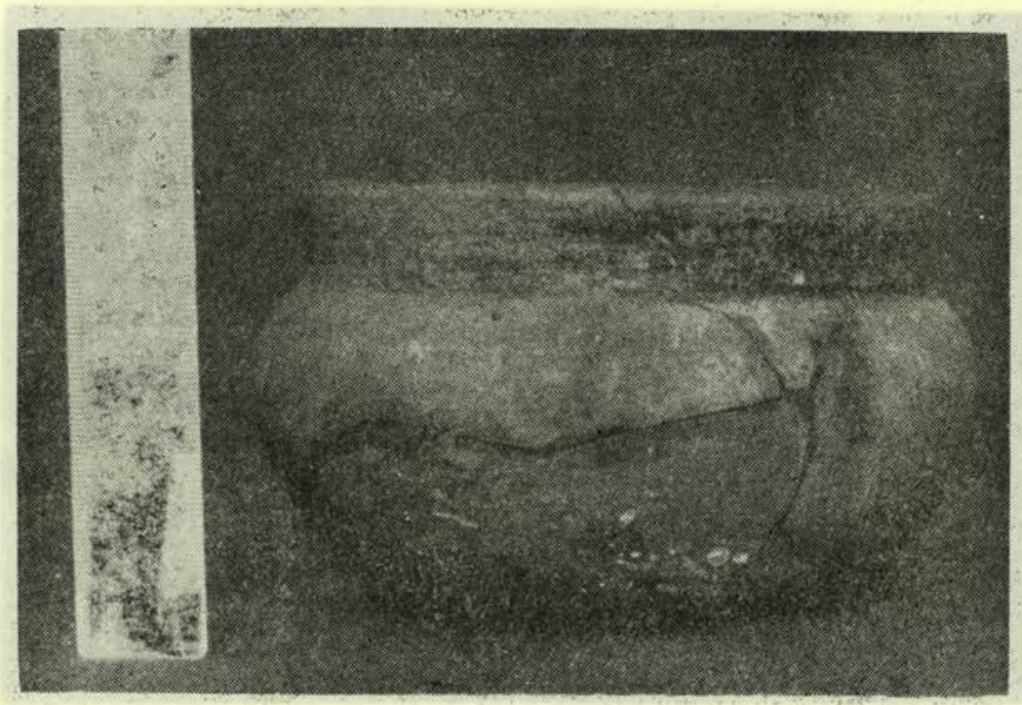

Figura 6. Objeto 12 
Tumba del Templo de las Inscripciones (Rands 1974a: Fig. 7a; Ruz 1952: 13, 1973: Fig. 188-190), correspondientes cronológicamente a la faceta tardía del Ilustración: Figura 6. complejo Otolum (Rands Op. cit.: 63).

Número de Objeto 13.

Procedencia y/o número de catálogo: 1953, Templo de la Cruz Foliada, escombro que cubría el pórtico, sobre el piso (Ruz 1953: 9-10); Cat. 105 B.

Forma: Brasero con borde redondo, paredes rectas divergentes, fondo ligeramente cóncavo, soporte de pedestal con perforaciones triangulares. El diámetro del borde es de $15.5 \mathrm{~cm}$, el de la base de $8.6 \mathrm{~cm}$ y la altura de $9 \mathrm{~cm}$.

Pasta: Pasta de textura media con desgrasante de cuarzo, inclusiones de mica, color café claro (7.5 YR 6/4).

Acabado de la superficie y decoración: Las superficies están alisadas y cubiertas con una baño blanco; prácticamente toda la pieza está ahumada.

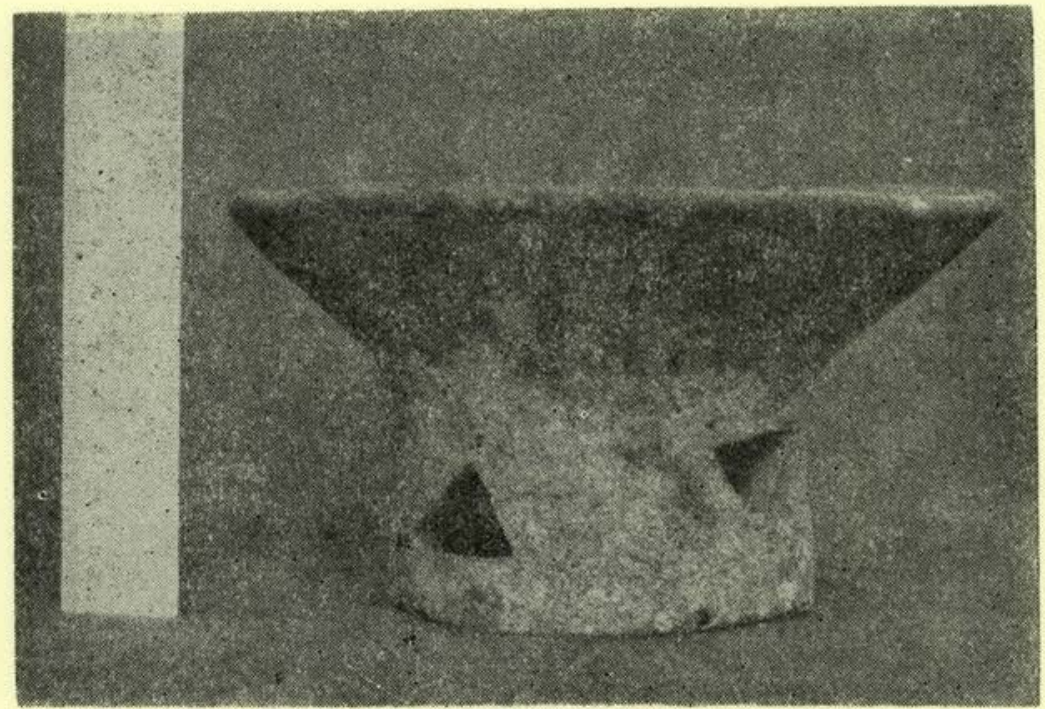

Figura 7. Objeto 13 
Complejo: El Templo de la Cruz está fechado en 690 d.C., por lo cual es factible que el objeto aquí catalogado corresponda al complejo Murciélagos.

Ilustración: Figura 7.

Número de Objeto: 14.

Procedencia y/o número de catálogo: Pal. 136, Pal. A 11: 14; Cat. 557.

Forma: Cajete de paredes semiesféricas, borde directo cuadrado, fondo convexo y base cóncava. El diámetro del borde es de $15.8 \mathrm{~cm}$, el de la base de $6.2 \mathrm{~cm}$ y la altura de $6 \mathrm{~cm}$.

Pasta: Pasta de textura media con desgrasante de arena de cuarzo, color café rojizo claro (5 YR 6/4).

Acabado de la superficie y decoración: Las superficies están alisadas y cubiertas con un baño blanco.

Complejo: Rands (1974a: Fig. 5g) ilustra cajetes de paredes semiesféricas solamente para el complejo Motiepa. Ruz (1973: 134) señala que estas formas son poco comunes, indicando que cronológicamente "aparecen antes de Las Inscripciones".

En la ofrenda I del Templo V del Grupo Norte dos objetos, supuestamente con decoración negativa (Ruz 1958a: Fig. 9b, 9e), son similares en forma al aquí catalogado. En la ofrenda mencionada también hay cajas, rectangulares o cilíndricas, que cronológicamente hemos ubicado en el complejo Murciélagos (véase el apartado correspondiente a Complejo en la cédula del Objeto 1 ).

Ilustración: Figura 5.

Número de Objeto: 15.

Procedencia y/o número de catálogo: Entierro II No. 2, T. XVIII, Pal. 1954 (Ruz 1954: Fig. 32b); Cat. 1056 B.

Forma: Vaso con borde directo redondo, paredes rectas con ligera curvatura externa, fondo y base planos. El diámetro del borde es de $9.2 \mathrm{~cm}$, el de la base de $8.2 \mathrm{~cm}$ y la altura de $11.4 \mathrm{~cm}$. 
Pasta: Pasta de textura fina con desgrasante de cuarzo, color rojo (2.5 YR 4/8), con núcleo delgado café rojizo (2.5 YR 4/4).

Acabado de la superficie y decoración: Las superficies están alisadas.

Complejo: Balunté Temprano (Rands 1974a: Fig. 10 d).

Observaciones: Hay otros dos objetos con esta misma forma que hemos catalogado como sigue: Objeto 16, caja de piedra 1, T. XVIII, Pal. 1954, Catálogo 555 D, incompleto, el diámetro de la base es de $7 \mathrm{~cm}$; Objeto 17, Cat. $517 \mathrm{R}$, incompleto.

Ilustración: Figura 8.

Número de Objeto: 18 .

Procedencia y/o número de catálogo: 1956, Norte V, Of. 1-8; Cat. 517 B.

Forma: Caja cilíndrica con reborde labial, fondo y base planos, el diámetro del borde es de $6.6 \mathrm{~cm}$, el de la base de $6.9 \mathrm{~cm}$ y la altura de $5.6 \mathrm{~cm}$.

Pasta: Pasta de textura media con desgrasante de cuarzo, color café grisáceo oscuro (10 YR 4/2).

Acabado de las superficies y decoración: Las superficies están alisadas y cubiertas con un engobe rojizo.

Complejo: Murciélagos (véase el apartado correspondiente a Complejo en la cédula del Objeto 1).

Ilustración: Figura 8.

Número de Objeto: 19.

Procedencia y/o número de catálogo: Pal. 1954, T. XIII, escombro; Cat. 520.

Forma: Vaso cilíndrico de base y fondo planos. El diámetro de la base es de $8.5 \mathrm{~cm}$.

Pasta: Pasta de textura fina con desgrasante de cuarzo, color rojo claro (2.5 YR 6/8) con núcleo delgado café amarillento (10 YR 5/4).

Acabado de la superficie y decoración: Las superficies están alisadas, aparentemente sin engobe. La decoración es incisa y punzonada con motivos geométricos rectilíneos, a manera de grecas, en una banda horizontal, en 


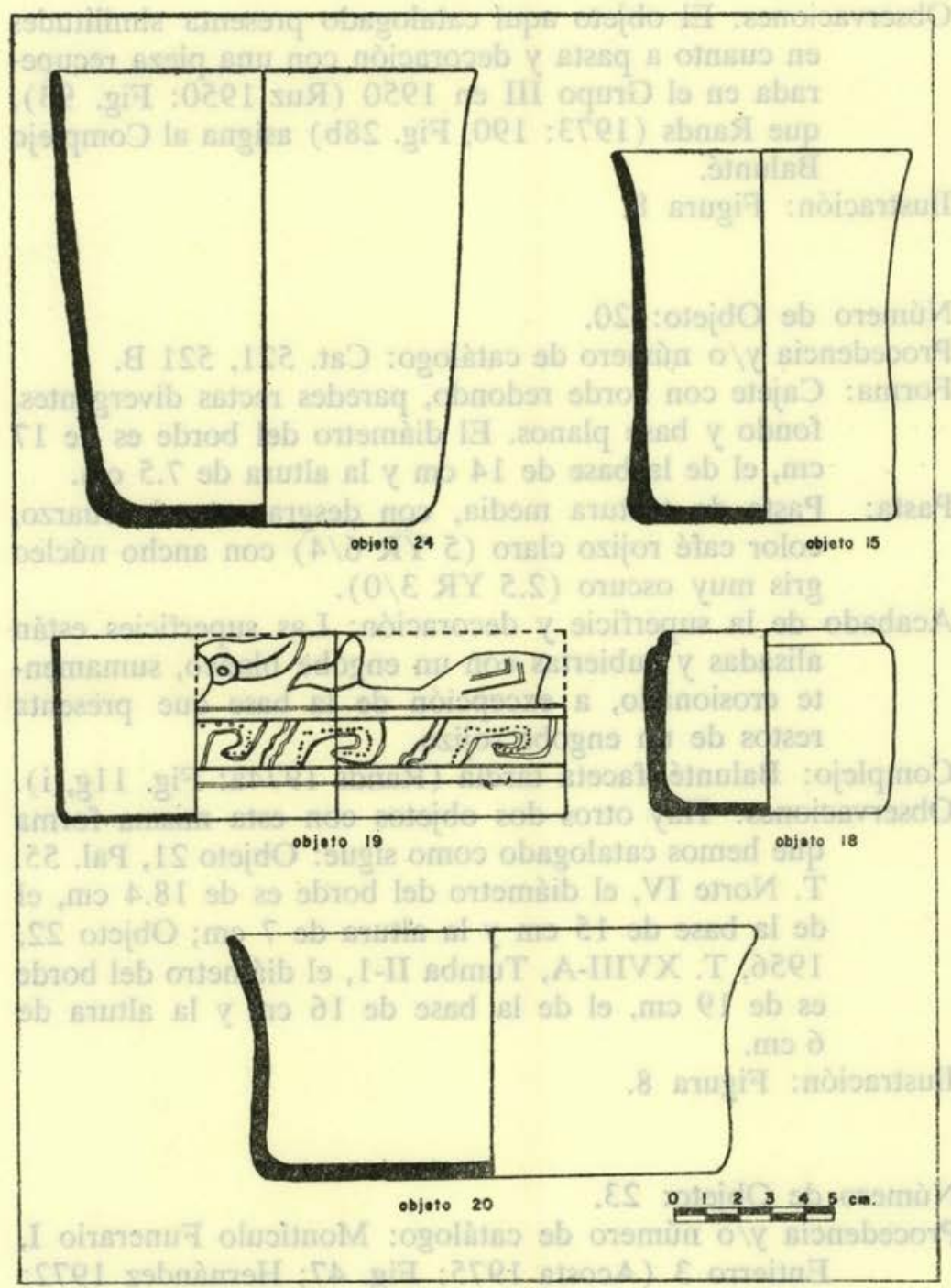

Figura 8

tanto que se aprecia parte de motivos curvilíneos y rectilíneos en el cuerpo.

Complejo: Durante el complejo Balunté hay decoración incisa combinada con estampado dentado en zonas (Rands 1974b: 38). 
Observaciones: El objeto aquí catalogado presenta similitudes en cuanto a pasta y decoración con una pieza recuperada en el Grupo III en 1950 (Ruz 1950: Fig. 93), que Rands (1973: 190, Fig. 28b) asigna al Complejo Balunté.

Ilustración: Figura 8.

Número de Objeto: 20.

Procedencia y/o número de catálogo: Cat. 521, 521 B.

Forma: Cajete con borde redondo, paredes rectas divergentes, fondo y base planos. El diámetro del borde es de 17 $\mathrm{cm}$, el de la base de $14 \mathrm{~cm}$ y la altura de $7.5 \mathrm{~cm}$.

Pasta: Pasta de textura media, con desgrasante de cuarzo, color café rojizo claro (5 YR 6/4) con ancho núcleo gris muy oscuro (2.5 YR 3/0).

Acabado de la superficie y decoración: Las superficies están alisadas y cubiertas con un engobe blanco, sumamente erosionado, a excepción de la base que presenta restos de un engobe rojizo.

Complejo: Balunté, faceta tardía (Rands 1974a: Fig. 11g, i). Observaciones: Hay otros dos objetos con esta misma forma que hemos catalogado como sigue: Objeto 21, Pal. 55, T. Norte IV, el diámetro del borde es de $18.4 \mathrm{~cm}$, el de la base de $15 \mathrm{~cm}$ y la altura de $7 \mathrm{~cm}$; Objeto 22 , 1956, T. XVIII-A, Tumba II-1, el diámetro del borde es de $19 \mathrm{~cm}$, el de la base de $16 \mathrm{~cm}$ y la altura de $6 \mathrm{~cm}$.

Ilustración: Figura 8.

Número de Objeto: 23.

Procedencia y/o número de catálogo: Montículo Funerario I, Entierro 3 (Acosta 1975: Fig. 47; Hernández 1972: $1,5)$.

Forma: Plato trípode con borde evertido en ángulo recto, cuerpo semiesférico, base cóncava, fondo ligeramente convexo, soportes sólidos cónico redondeados. El diámetro del borde es de $19.3 \mathrm{~cm}$ y la altura de $4 \mathrm{~cm}$.

Pasta: Pieza completa, por lo que no fue posible determinar las características de la pasta. 
Acabado de la superficie y decoración: Las superficies están alisadas y aparentemente cubiertas con un engobe blanco, sumamente erosionado.

Es posible que se trate de una vasija con decoración policroma.

Complejo: El objeto aquí catalogado es similar en forma a platos trípodes con decoración policroma recuperados en la tumba del Templo de las Inscripciones (Ruz 1952: 13; 1973: Fig. 188-190), que cronológicamente corresponden al Complejo Otolum Tardío (Rands 1974a: Fig. 7a).

Ilustración: Figura 9.

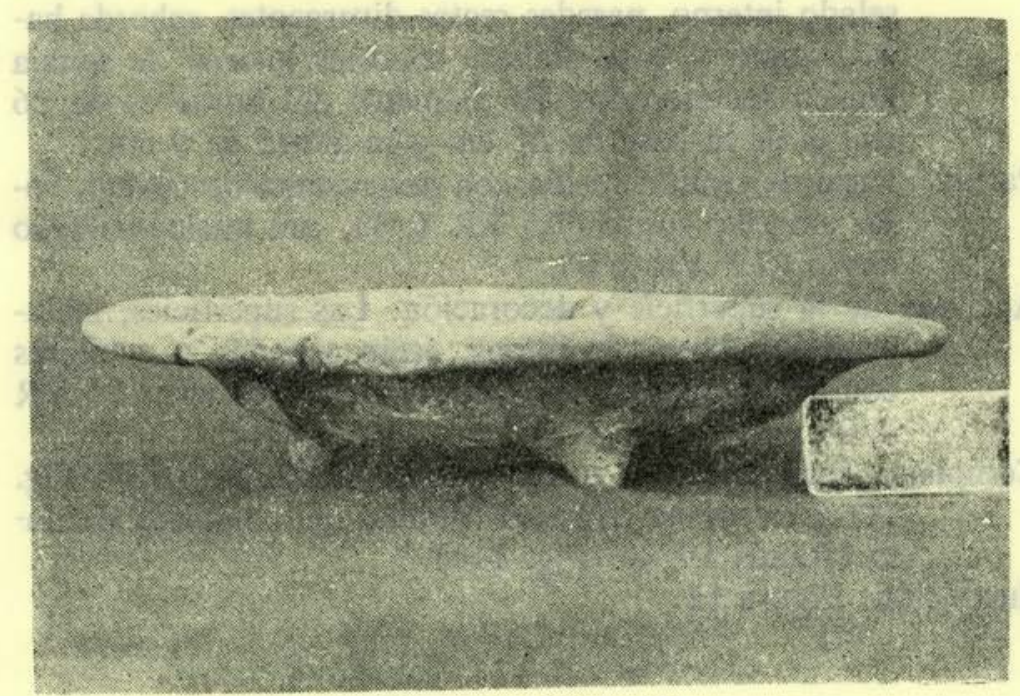

Figura 9. Objeto 23

Número de Objeto: 24.

Procedencia y/o número de catálogo: No determinados.

Forma: Vaso con borde directo redondo, paredes ligeramente rectas divergentes, fondo y base planos. El diámetro del borde es de $13.2 \mathrm{~cm}$, el de la base de $10.9 \mathrm{~cm}$ y la altura de $13.6 \mathrm{~cm}$.

Pasta: Pasta de textura media con desgrasante de cuarzo e inclusiones de mica, color rojo (2.5 YR 5/6), con núcleo delgado café claro (7.5 YR 6/4). 
Acabado de la superficie y decoración: Las superficies están alisadas y, a excepción de la base, cubiertas con un engobe café rojizo pulido.

Complejo: Probablemente Otolum Tardío (Rands 1974a: Fig. $7 d)$.

Ilustración: Figura 8.

Número de Objeto: 25 .

Procedencia y/o número de catálogo: Grupo III, Cuarto 2, sobre piso, ofrenda 11, 1950 (Zavala 1950: 11); Cat. $517,558 \mathrm{~A}, 558 \mathrm{~B}$.

Forma: Plato trípode con borde ligeramente evertido con biselado interno, paredes rectas divergentes, reborde basal, fondo y base planos, soportes huecos de sonaja cónico redondeados. El diámetro del borde es de 26 $\mathrm{cm}$, el de la base de $21 \mathrm{~cm}$ y la altura de $9 \mathrm{~cm}$.

Pasta: Pasta de textura media con desgrasante de cuarzo, color amarillo rojizo (7.5 YR 6/6), con núcleo delgado negro (7.5 YR 2/0).

Acabado de la superficie y decoración: Las superficies, incluyendo la base y soportes, están alisadas y cubiertas con un engobe que varía de rojo a gris oscuro (2.5 YR $4 / 0)$.

Complejo: Esta forma es tardía (Rands \& Rands 1957: Fig. 1f) y es similar a platos trípodes del complejo Balunté (Rands 1974a: Fig. 11c).

Ilustración: Figura 11.

Número de Objeto: 26.

Procedencia y/o número de catálogo: Templo IV, Grupo Norte (Ruz 1957: Fig. 16b); Cat. 555 F.

Forma: Olla con borde invertido aplanado, con ensanchamiento externo, cuerpo semiesférico. El diámetro del borde es de $22 \mathrm{~cm}$.

Pasta: Pasta de textura media, con desgrasante de cuarzo, color café claro (7.5 YR 6/4), con núcleo ancho gris muy oscuro (2.5 Y 3/0).

Acabado de la superficie y decoración: Las superficies están alisadas, apreciándose manchas de cocción. 
Complejo: En el complejo Motiepa hay jarras cuya forma es similar al objeto aquí catalogado (Rands 1974a: Fig. $6 c)$.

Observaciones: Hay otro tiesto con esta misma forma (Cat. $557 \mathrm{k}$ ), catalogado como Objeto 27.

Ilustración: Figura 11.

Número de Objeto: 28.

Procedencia y/o número de catálogo: Entierro II, No. 1, T. XVIII, Pal. 1954; Cat. 522.

Forma: Plato trípode con borde semievertido con biselado interno, paredes rectas divergentes, fondo y base planos, soportes cónicos redondeados sólidos. El diámetro del borde es de $27.6 \mathrm{~cm}$, el de la base de $20.7 \mathrm{~cm}$ y la altura de $5.7 \mathrm{~cm}$.

Pasta: Pasta de textura media, con desgrasante de arena de cuarzo, color rojo (2.5 YR 5/6).

Acabado de la superficie y decoración: Las superficies están alisadas y aparentemente carecen de engobe.

Complejo: Balunté Temprano (Rands 1974a: Fig. 11h). Ilustración: Figura 10.

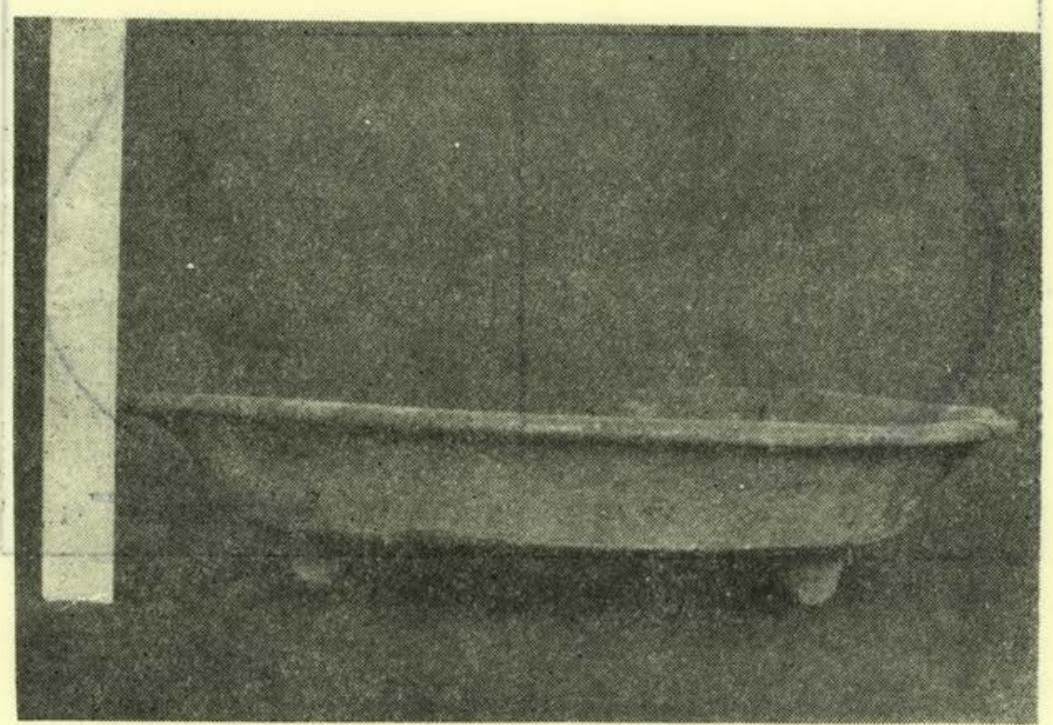

Figura 10. Objeto 28 


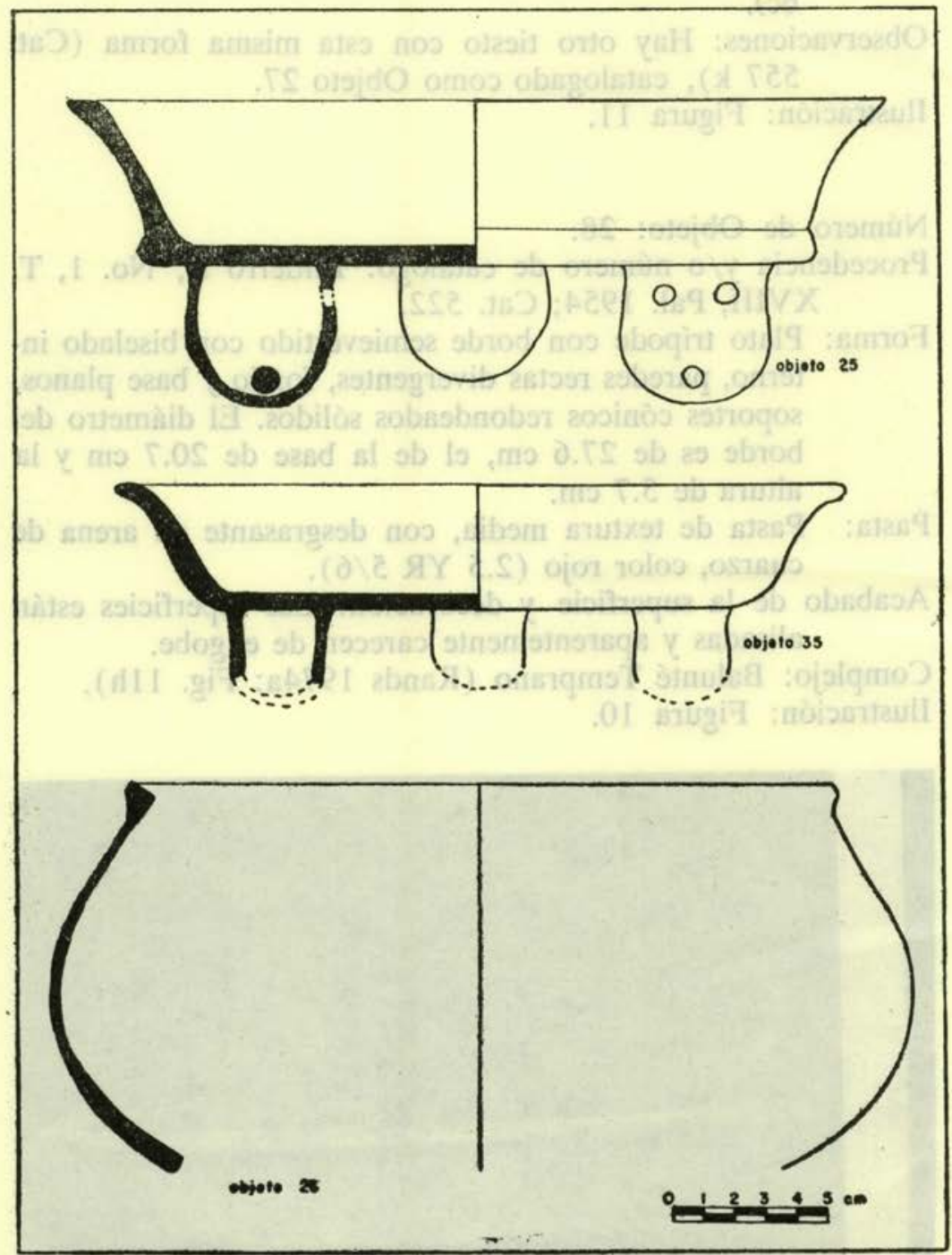

Figura 11

Estudios de Cultura Maya. Vol. XVIII, 1991

Instituto de Investigaciones Filológicas/

Centro de Estudios Mayas, UNAM 


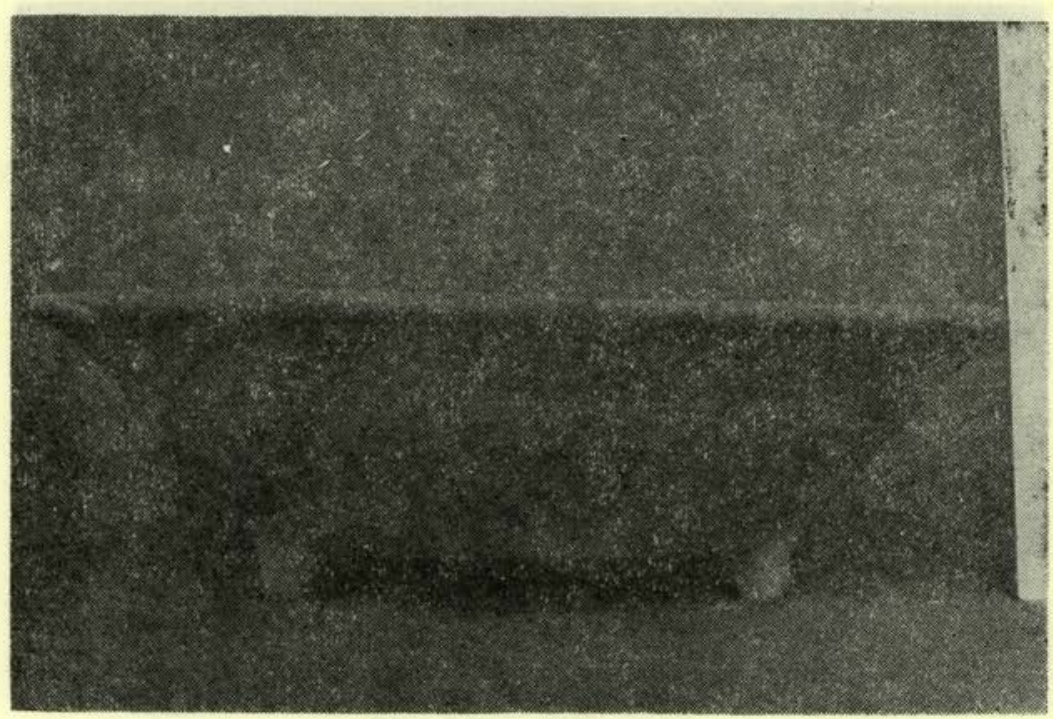

Figura 12. Objeto 29

Número de Objeto: 29.

Procedencia y/o número de catálogo: Pal-57, XVIII-A, T. III, No. 4; Cat. 516.

Forma: Cajete trípode con borde ligeramente evertido con biselado interno, cuerpo semiesférico, fondo cóncavo, base ligeramente convexa, soportes sólidos cilíndricos. El diámetro del borde es de $28.3 \mathrm{~cm}$, el de la base de $17.2 \mathrm{~cm}$ y la altura de $8.5 \mathrm{~cm}$.

Pasta: Pieza completa, por lo que no fue posible determinar las características de la pasta.

Acabado de la superficie y decoración: Las superficies están alisadas.

Complejo: Motiepa (Rands 1974a: Fig. 5e).

Ilustración: Figura 12.

Número de Objeto: 30 .

Procedencia y/o número de catálogo: Pal-54, XVIII-A, T. III, No. 42 ; Cat. 553.

Forma: Plato con borde directo redondo, con biselado interno y ligero ensanchamiento externo, paredes rectas divergentes, fondo cóncavo y base plana. El diámetro 


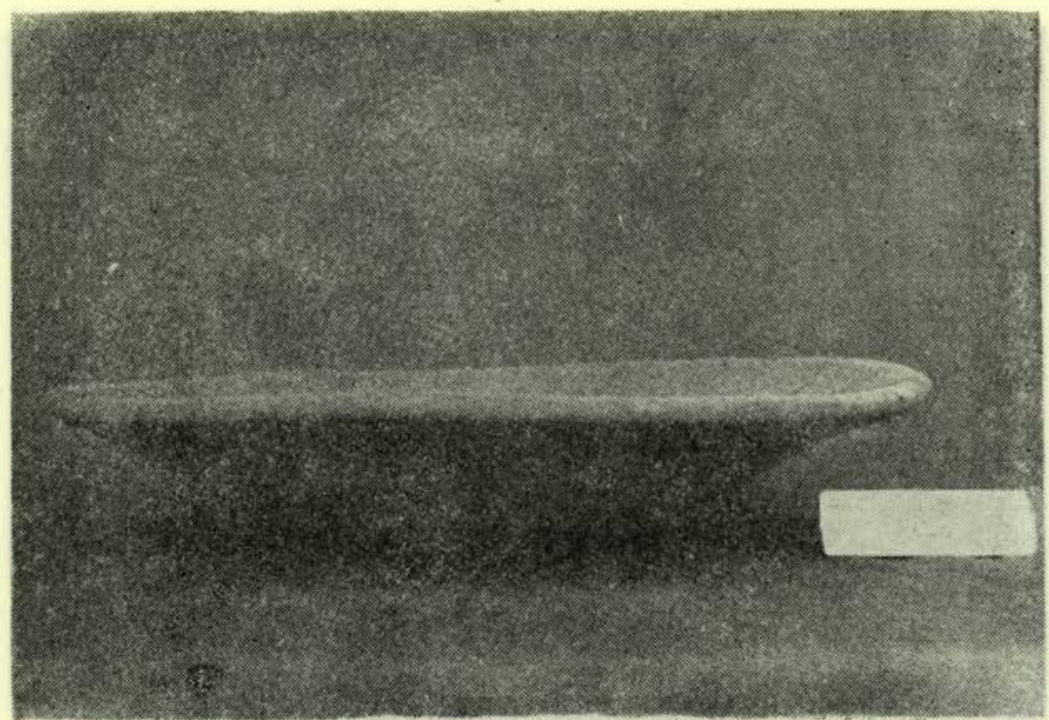

Figura 13. Objeto 30

del borde es de $29.7 \mathrm{~cm}$, el de la base de $7.5 \mathrm{~cm}$ y la altura de $5.7 \mathrm{~cm}$.

Pasta: Pasta de textura media con desgrasante de cuarzo, inclusiones de hematita y mica, color rojo (2.5 YR 5/8).

Acabado de la superficie y decoración: Las superficies están alisadas y se aprecian restos de engobe rojizo en el interior.

Complejo: Motiepa (Rands 1974a: Fig. 57).

Observaciones: Hay otros tres objetos con esta misma forma que hemos catalogado como sigue: Objeto 31, Cat. 557 F, E, L, incompleto, el diámetro del borde es de $30 \mathrm{~cm}$; Objeto 32 recuperado en el Templo XVIII-A, T. III, No. 2, Catálogo 552, el diámetro del borde es de $28 \mathrm{~cm}$, el de la base de $8.2 \mathrm{~cm}$ y la altura de 4.9 $\mathrm{cm}$; Objeto 33, recuperado en el Templo XVIII-A, Tumba III (Ruz 1959: Fig. 9d), Catálogo 554.

Ilustración: Figura 13.

Número de Objeto: 34.

Procedencia y/o número de catálogo: Grupo III, cámara 14-a, bajo el primer piso, ofrenda 12 (Zavala 1950: 20). 
Forma: Incensario con borde directo cuadrado, cuerpo recto divergente, fondo ligeramente convexo, soporte alto de pedestal con tres perforaciones circulares. El diámetro del borde es de $36 \mathrm{~cm}$ el de la base de 21.5 $\mathrm{cm}$, la altura del soporte de $10 \mathrm{~cm}$ y la altura total de $19.5 \mathrm{~cm}$.

Pasta: Pasta de textura media con desgrasante de cuarzo e inclusiones de hematita, color rojo (2.5 YR 5/6) y ancho núcleo gris rojizo oscuro (5 YR 4/2).

Acabado de la superficie y decoración: Las superficies están alisadas y cubiertas con un baño blanco. El fondo presenta impresión de textil (véase Rands \& Rands 1959: Fig. 1).

Complejo: En la ofrenda 12 de la cámara 14-a del Grupo III, el objeto aquí catalogado está asociado a una caja rectangular con tapa (Zavala 1950: 18-20). Este tipo de cajas se encontró en la ofrenda I del Templo V del Grupo Norte (Ruz 1958a: 5) y en la sección sureste del palacio (Sáenz 1979: 29), asociados a cajas cilíndricas con tapa, que cronológicamente correspon-

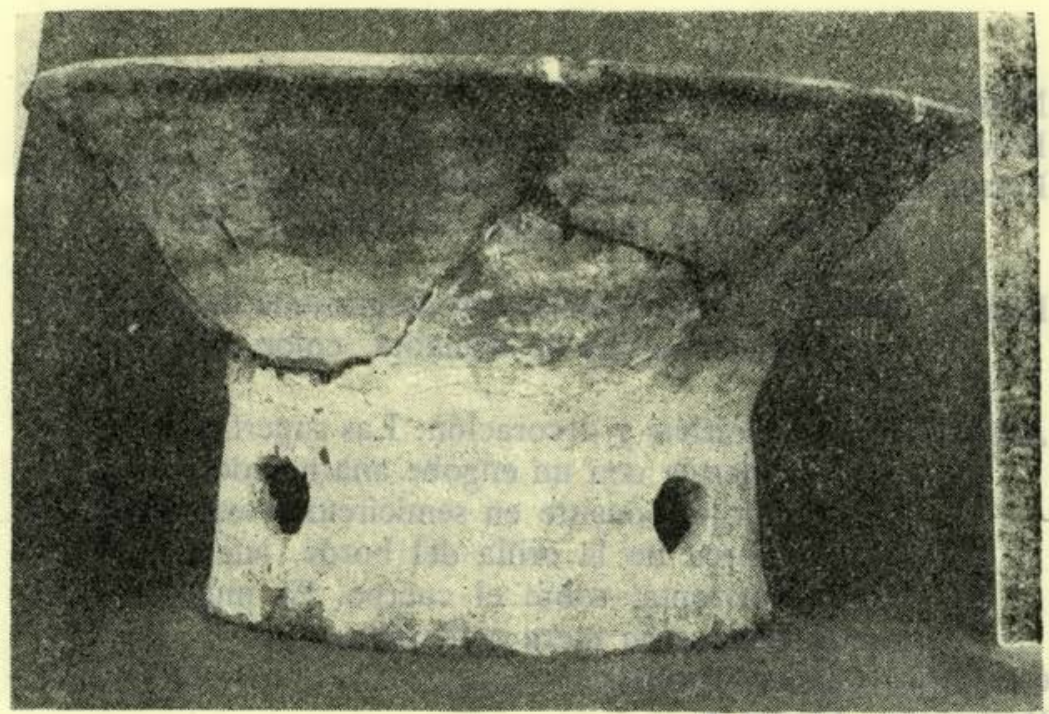

Figura 14. Objeto 34 
den al complejo Murciélagos (véase el apartado correspondiente a Complejo en la cédula del Objeto 1).

Ilustración: Figura 14.

Número de Objeto: 35 .

Procedencia y/o número de catálogo: Grupo Norte, Templo IV (Ruz 1957: Fig. 16f).

Forma: Plato trípode con borde semievertido con biselado interno, paredes rectas divergentes, fondo y base planos, soportes huecos de sonaja cónico redondeados. El diámetro del borde es de $23 \mathrm{~cm}$ y el de la base de $19.5 \mathrm{~cm}$.

Pasta: Pasta de textura media, con desgrasante de cuarzo, inclusiones de mica y hematita, color rojo (2.5 YR 5/6).

Acabado de la superficie y decoración: Las superficies están alisadas y cubiertas con engobe color rojo débil (10 R 5/3).

Complejo: Para el complejo Murciélagos hay platos cuya forma es similar al objeto aquí catalogado (Rands 1974a: Fig. 9a, b).

Ilustración: Figura 11.

Número de Objeto: 36 .

Procedencia y/o número de catálogo: Cat. 557 D.

Forma:Cajete con borde semievertido con biselado interno y paredes rectas divergentes. El diámetro del borde es de $22 \mathrm{~cm}$.

Pasta: Pasta de textura media, con desgrasante de calcita triturada e inclusiones de hematita, color rojo (2.5 YR $5 / 6)$.

Acabado de la superficie y decoración: Las superficies internas están cubiertas con un engobe anaranjado, la decoración, en rojo, consiste en semicírculos espaciados colocados cerca de la orilla del borde, además de una banda horizontal sobre el cuerpo. Es muy probable que la decoración fuera policroma.

Complejo: Clásico Tardío.

Ilustración: Figura 5. 


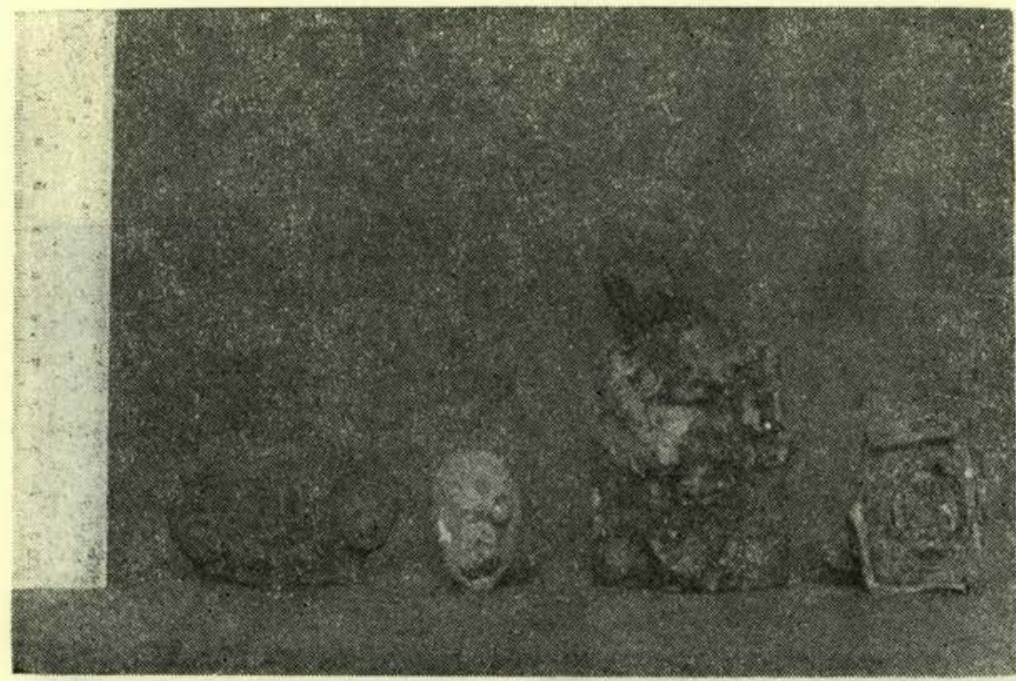

\section{FIGURILLAS}

Objeto 37: Cabeza de figurilla antropomorfa con orejeras, correspondiente al periodo Clásico (Rands \& Rands 1965: Fig. 47).

Ilustración: Figura 15.

Objeto 38: Cabeza sólida de figurilla grotesca o búho (?), correspondiente probablemente al Clásico Tardío (Willey 1978: Fig. 18).

Ilustración: Figura 15.

Objeto 39: Fragmento de figurilla antropomorfa con tocado elaborado de cabezas sobrepuestas, correspondiente al periodo Clásico (Rands \& Rands 1965: Fig. 44).

Ilustración: Figura 15.

Objeto 40: Fragmento de pendiente o sello con glifo impreso, posiblemente correspondiente al Clásico Tardío (Willey 1958: Fig. 53).

Ilustración: Figura 15. 


\section{6}

ESTUDIOS DE CULTURA MAYA, XVIII

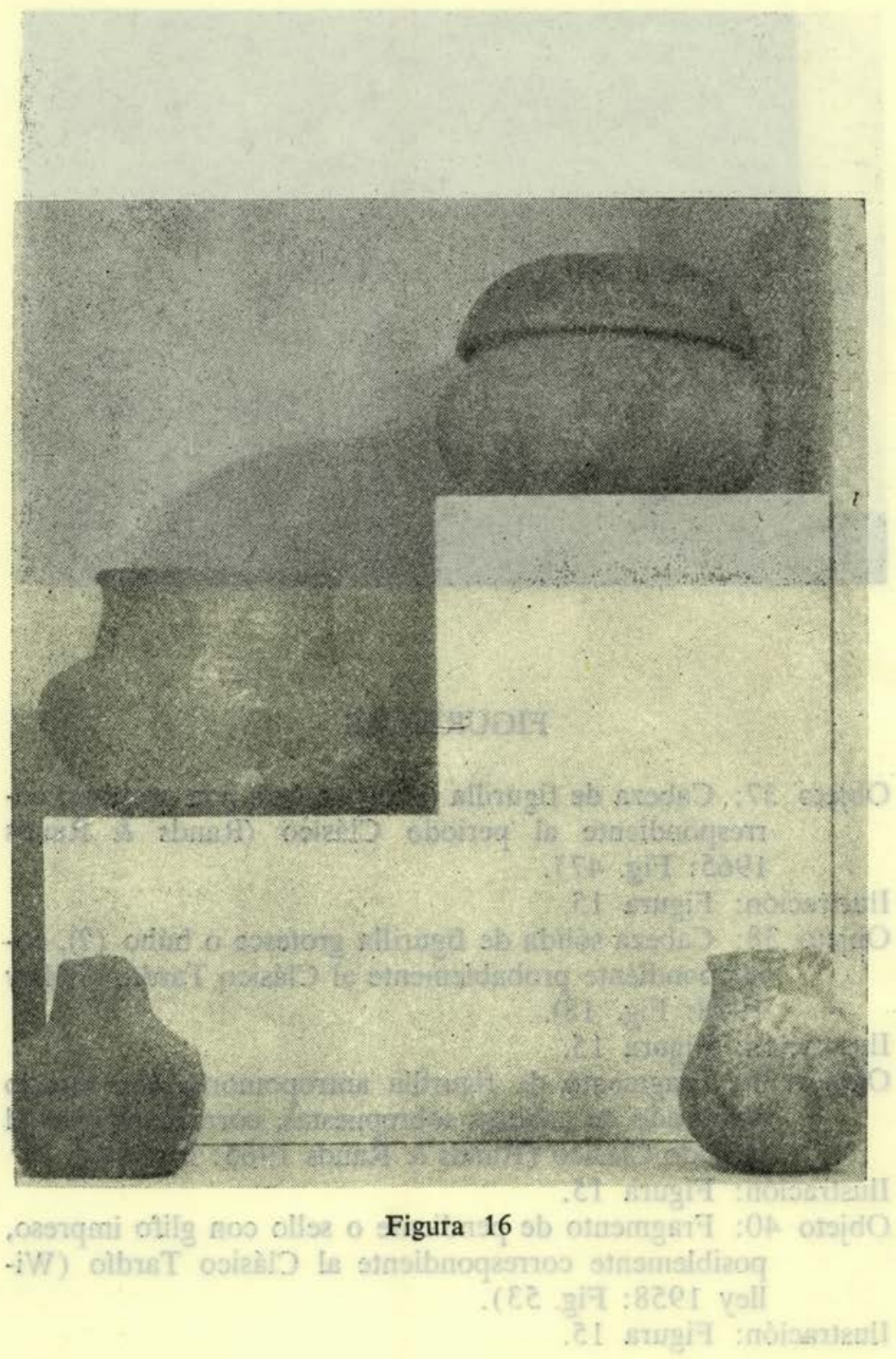

Estudios de Cultura Maya. Vol. XVIII, 1991

Instituto de Investigaciones Filológicas/

Centro de Estudios Mayas, UNAM

ISSN 0185-2574 


\section{Manejo electrónico de datos}

En la actualidad, se ha extendido cada vez más el uso de computadoras en las más diversas aplicaciones, por ejemplo: recreativas, industriales y científicas. Una de sus aplicaciones en las ciencias sociales es para la obtención de conteos y estadísticas diversas.

A fin de facilitar el trabajo de computación para el procesamiento de datos estadísticos provenientes de las ciencias sociales, entre ellas arqueología, existen diversos grupos unificados de "programas de computadora", esto es, conjuntos de instrucciones orientadas a la obtención de resultados específicos, uno de los cuales se utilizó en este caso y que es el Statistical Package for the Social Sciences: Paquete Estadístico para las Ciencias Sociales (SPSS).

Este paquete estadístico es fácil de utilizar y permite realizar diversos tipos de análisis estadístico, dependiendo de las necesidades especiales del estudio de que se trate. En muchos casos la gran variabilidad y volumen de los datos hace necesario tanto el empleo de la computadora como el uso de medidas y cuadros estadísticos para obtener información objetiva en forma rápida, eficiente y confiable. Como no es raro en arqueología que el investigador deba interpretar grandes volúmenes de datos, se ha venido utilizando cada vez más la computadora como una útil herramienta para la obtención de resultados estadísticos y para el control y manejo de los datos mismos.

Se presentan situaciones en las que el arqueólogo, sin requerir en forma específica medidas estadísticas, necesita tener listas de grupos de datos con alguna o algunas características comunes, como por ejemplo: procedencia o contexto, temporalidad, clase de objeto y particularidades del mismo, por citar algunas posibilidades. Esta labor se simplifica mucho al tener un archivo o grupo de datos donde estén anotadas estas características y que esté almacenado en un medio procesable por computadora, para aprovechar las capacidades de ésta a fin de obtener las listas deseadas y los conteos que se necesiten, a lo que se conoce como base de datos.

Para el catálogo de objetos cerámicos en la bodega de $\mathrm{Pa}$ lenque, se generó un pequeño archivo de datos que sirve para ejemplificar una aplicación del SPSS en arqueología y que además es susceptible de manejarse como una base de datos o de 
agregarse a otro $u$ otros archivos de este tipo, por ejemplo para la obtención de estadísticas, listas o conteos correspondientes a varios sitios arqueológicos.

A fin de realizar esta aplicación se asignó una clave (numérica o alfabética) a cada uno de los datos correspondientes a cada objeto del catálogo, y este conjunto en clave o codificado se introdujo a la memoria de la computadora. A continuación se encuentra la impresión o listado de dichos datos (véase Listado 1).

Este archivo de datos, como ya se mencionó, se procesó usando SPSS, específicamente la subrutina "FREQUENCIES" o FRECUENCIAS, complementada con la de "Crosstabs" o tablas CRUZADAS, para obtener conteos y porcentajes referentes a cada una de las características o atributos de los objetos cerámicos en consideración, o bien para comparar pares de atributos. Para que resulte clara la forma en que se utiliza el paquete en un trabajo de este tipo, se incluye lo que se acostumbra denominar "programa SPSS" en donde, entre otras instrucciones, se anota cuál es el encabezado o "etiqueta" para los diferentes atributos de los objetos y para las distintas variaciones de dichos atributos (véase Listado 2).

Del procesamiento de los datos usando este programa, puede llegarse a las conclusiones que se presentan a continuación.

\section{LISTADO 1}

$\begin{array}{clllllllllllllll}1 . & 01 & 01 & \text { FCT } & \text { N } & 02 & 01 & 1 & 1 & 9 & 9 & 9 & 21 & 2 & 6 & 08 \\ \text { 2. } & 02 & 01 & \text { FJA } & \text { M } & 03 & 02 & 1 & 1 & 1 & 1 & 9 & 99 & 3 & 6 & 08 \\ 3 . & 03 & 11 & \text { FCJ } & \text { M } & 03 & 04 & 1 & 2 & 9 & 9 & 9 & 99 & 3 & 6 & 10 \\ 4 . & 04 & 02 & \text { FJA } & \text { M } & 10 & 02 & 1 & 6 & 2 & 1 & 1 & 21 & 1 & 6 & 08 \\ \text { 5. } & 05 & 02 & \text { FCJ } & \text { M } & 05 & 04 & 2 & 1 & 9 & 9 & 9 & 21 & 3 & 6 & 08 \\ 6 . & 06 & 02 & \text { FCJ } & \text { M } & 05 & 04 & 2 & 1 & 9 & 9 & 9 & 21 & 3 & 6 & 08 \\ 7 . & 07 & 03 & \text { FCJ } & \text { M } & 03 & 02 & 3 & 1 & 9 & 9 & 9 & 31 & 3 & 6 & 08 \\ 8 . & 08 & 02 & \text { FCJ } & \text { N } & 03 & 02 & 4 & 3 & 9 & 9 & 9 & 99 & 3 & 6 & 08 \\ 9 . & 09 & 02 & \text { FCJ } & \text { N } & 11 & 07 & 4 & 3 & 9 & 9 & 9 & 11 & 3 & 6 & 08 \\ 10 . & 10 & 02 & \text { FVC } & \text { N } & 06 & 07 & 1 & 1 & 9 & 9 & 9 & 99 & 1 & 6 & 08 \\ 11 . & 11 & 04 & \text { FVC } & \text { N } & 06 & 07 & 1 & 1 & 9 & 9 & 9 & 21 & 1 & 6 & 08 \\ 12 . & 12 & 05 & \text { FCJ } & \text { N } & 04 & 02 & 4 & 3 & 9 & 9 & 9 & 11 & 1 & 1 & 05 \\ 13 . & 13 & 04 & \text { FIN } & \text { N } & 04 & 08 & 3 & 1 & 9 & 9 & 2 & 21 & 3 & 6 & 08 \\ 14 . & 14 & 11 & \text { FCJ } & \text { N } & 03 & 02 & 4 & 3 & 9 & 9 & 9 & 21 & 3 & 6 & 08 \\ 15 . & 15 & 06 & \text { FVC } & \text { N } & 04 & 04 & 1 & 1 & 9 & 9 & 9 & 11 & 1 & 6 & 11 \\ 16 . & 16 & 06 & \text { FVC } & \text { N } & 04 & 04 & 1 & 1 & 9 & 9 & 9 & 11 & 1 & 6 & 11\end{array}$




$\begin{array}{llllllllllllllll}17 . & 17 & 11 & \text { FVC } & \text { N } & 04 & 04 & 1 & 1 & 9 & 9 & 9 & 11 & 1 & 6 & 11 \\ 18 . & 18 & 02 & \text { FCT } & \text { N } & 02 & 01 & 1 & 1 & 9 & 9 & 9 & 21 & 2 & 6 & 08 \\ 19 . & 19 & 07 & \text { FVC } & \text { N } & 11 & 01 & 1 & 1 & 9 & 9 & 9 & 11 & 1 & 3 & 10 \\ 20 . & 20 & 11 & \text { FCJ } & \text { N } & 04 & 08 & 1 & 1 & 9 & 9 & 9 & 21 & 2 & 6 & 12 \\ 21 . & 21 & 09 & \text { FCJ } & \text { N } & 04 & 08 & 1 & 1 & 9 & 9 & 9 & 21 & 2 & 6 & 12 \\ 22 . & 22 & 10 & \text { FCJ } & \text { N } & 04 & 08 & 1 & 1 & 9 & 9 & 9 & 21 & 2 & 6 & 12 \\ 23 . & 23 & 05 & \text { FPL } & \text { N } & 07 & 02 & 4 & 3 & 9 & 9 & 4 & 99 & 2 & 6 & 05 \\ 24 . & 24 & 11 & \text { FVC } & \text { N } & 04 & 08 & 1 & 1 & 9 & 9 & 9 & 21 & 2 & 6 & 06 \\ 25 . & 25 & 08 & \text { FPL } & \text { N } & 10 & 08 & 1 & 5 & 9 & 9 & 3 & 21 & 2 & 6 & 10 \\ 26 . & 26 & 09 & \text { FOL } & \text { N } & 09 & 02 & 5 & 6 & 9 & 9 & 9 & 21 & 1 & 6 & 01 \\ 27 . & 27 & 11 & \text { FOL } & \text { N } & 09 & 02 & 5 & 6 & 9 & 9 & 9 & 21 & 1 & 6 & 01 \\ 28 . & 28 & 06 & \text { FPL } & \text { N } & 10 & 08 & 1 & 1 & 9 & 9 & 4 & 21 & 1 & 6 & 11 \\ 29 . & 29 & 10 & \text { FCJ } & \text { N } & 10 & 02 & 3 & 7 & 9 & 9 & 5 & 99 & 1 & 6 & 01 \\ 30 . & 30 & 10 & \text { FPL } & \text { N } & 04 & 08 & 3 & 1 & 9 & 9 & 9 & 21 & 2 & 6 & 01 \\ 31 . & 31 & 11 & \text { FCJ } & \text { N } & 04 & 08 & 3 & 1 & 9 & 9 & 9 & 21 & 2 & 6 & 01 \\ 32 . & 32 & 10 & \text { FCJ } & \text { N } & 04 & 08 & 3 & 1 & 9 & 9 & 9 & 21 & 2 & 6 & 01 \\ 33 . & 33 & 10 & \text { FCJ } & \text { N } & 04 & 08 & 3 & 1 & 9 & 9 & 9 & 21 & 2 & 6 & 01 \\ 34 . & 34 & 08 & \text { FIN } & \text { N } & 03 & 08 & 4 & 6 & 9 & 9 & 2 & 21 & 3 & 7 & 08 \\ 35 . & 35 & 09 & \text { FPL } & \text { N } & 10 & 08 & 1 & 1 & 9 & 9 & 3 & 21 & 2 & 6 & 08 \\ 36 . & 36 & 11 & \text { FCJ } & \text { N } & 10 & 08 & 5 & 6 & 9 & 9 & 9 & 21 & 2 & 1 & 07 \\ 37 . & 37 & 11 & \text { FIG } & \text { N } & 11 & 10 & 5 & 6 & 9 & 9 & 9 & 99 & 1 & 2 & 07 \\ 38 . & 38 & 11 & \text { FIG } & \text { N } & 11 & 10 & 5 & 6 & 9 & 9 & 9 & 99 & 1 & 2 & 07 \\ 39 . & 39 & 11 & \text { FIG } & \text { N } & 11 & 10 & 5 & 6 & 9 & 9 & 9 & 99 & 1 & 2 & 07 \\ 40 . & 40 & 11 & \text { FSE } & \text { N } & 11 & 10 & 5 & 6 & 9 & 9 & 9 & 99 & 1 & 7 & 07\end{array}$

\section{LISTADO 2}

1. ¡Job Palenque, CSHD5/Lac. CSHD; outclass=LP, 1

2. !Run SPSS, Pub. SPSS

3. File name Pal "catálogo de objetos cerámicos en bodega, Pal, Chis."

4. Variable List. Numob, Proc, forma, sufforma, borde, cuerpo, fondo, base,

5. cuello, hombro, soportes, texpasta, compasta,

6. acabado, Tecdec, complejo

7. Input medium Disk (Dapal)

8. Input format Fixed (F2, 0, 1X, F2, 0, 1X, A1, 1X, 2 (F2, 0, 1X),

9. 5 (F1, 0, 1X), 2 (F1, 0), 1X, 2 (F1.0), 1X, 2 (F1.0, 1X), F2.0)

10. $\mathrm{N}$ of cases Unknown

11. Var labels Numob, número del objeto/

12. Proc, procedencia/

13. Sufforma, sufijo forma/

14. Texpasta, textura pasta/

15. Compasta, composición pasta/

16. Tecdec, técnica decorativa/

17. Value labels Proc (1) ED XIV (2) norte V (3) Prob norte V

18. (4) $\mathrm{T}$ cruz foliada (5) Mont funerario $I$ 
19. (6) T XVIII (7) T XIII (8) GPO III (9) norte IV (10) XVIII A

20. (11) no especificada/

21. Forma ('FJA') jarra ('FCJ') cajete

22. ('FCT') caja Cil. con tapa ('FPL') plato

23. ('FCU') cuenco ('FVC') vaso

24. ('FVU') $\mathrm{V}$ de paredes curvas convergentes

25. ('FOL') olla ('FIG') figurilla ('FIN') incensario

26. ('FTP') tapa ('FSE') sello ('FTP') plato trípode/

27. Sufforma ('N') normal ('M') miniatura/

28. Borde (2. reborde labial

29. (3) directo cuadrado (4) directo redondo

30. (5) redondo Lig. evertido (6) biselado Ext.

31. (7) Evert. en Ang. recto

32. (9) invertido aplanado (10) Evert. con Bis. Int.

33. (11) no determinable/

34. Cuerpo (1) cilíndrico (2) semiesférico

35. (4) recto con Curv. Ext.

36. (7) curvo convergente

37. (8) recto divergente

38. (9) recto con Curv. Ext.

39. (10) no determinable/

40. Fondo (1) plano (2) concavidad central

41. (3) cóncavo (4) convexo (5) no determinable/

42. Base (1) plana (2) cóncava con reborde (3) cóncava (7) convexa

43. (5) plana con reborde (6) no determinable/

44. Cuello (1) cuello (2) cóncavo corto (3) corto (9) sin cuello/

45. Hombro (1) bajo (9) sin hombro/

56. Soportes (1) anular (2) de pedestal

47. (3) cónicos huecos

48. Cónicos sólidos

49. (5) cílíndricos sólidos

50. (6) cónico (9) sin soportes/

51. Texpasta (1) fina (2) media (3) burda (9) no determinable/

52. Compasta (1) Cont. cuarzo (2) no Cont. cuarzo

53. (9) no determinable/

54. Acabado (1) sin engobe (2) con engobe

55. (3) con banio/

56. TECDEC (1) pintado (2) pastilla (3) inciso-punzonado

57. (6) sin decoración

58. (7) impresión/

59. Complejo (1) motiepa

60. (5) Otolum tardío (6) Prob. Otolum Tard.

61. (7) Prob. Otolum-Murciélagos

62. (8) Murciélagos

63. (9) Prob. Murcieiagos

64. (10) Balunte

65. (11) Balunte temprano

66. (12) Balunte tardío 
67. Missing values Proc., borde, cuerpo (11) fondo (5)

68. Base, TECDEC (6) cuello, hombro, soportes,

69. Texpasta, compasta (9)

70. Print formats forma, sufforma (A)

71. Frequencies General=Pro., forma, sufforma, borde, cuerpo,

72. Fondo, base, cuello, hombro, soportes, texpasta,

73. Compasta, acabado, TECDEC, complejo

74. Crossiabs Tables =forma by complejo/

75. Forma by borde/

76. Forma by cuerpo/

77. Forma by fondo/

78. Forma by base

79. Read input data

80. Finish

81. !EOJ

\section{Comentarios sobre frecuencias}

En lo referente a frecuencias por procedencia (véase Listado 3 ), dado que muchos de los materiales catalogados ya no contaban con información para determinar el contexto de donde provenían, el $30 \%$ está constituido por objetos con procedencia no especificada. En cuanto a las procedencias que sí fue posible definir, las más representadas son: el Edificio $\mathrm{V}$ del Grupo Norte con $17.5 \%$, el Edificio XVIII-A con $12.5 \%$, el Templo XVIII con $7.5 \%$ y el Edificio IV del Grupo Norte también con $7.5 \%$. Es interesante hacer notar que seis de los objetos procedentes del Edificio V del Grupo Norte se recuperaron en una misma ofrenda, es decir la I, mientras que los del Edificio XVIII-A, salvo un objeto, corresponden a la Tumba III que es semejante a la del Templo de las Inscripciones, en tanto que los objetos del Templo XVIII se recuperaron en el contexto de tumbas y entierros.

En lo que respecta a frecuencias por forma (véase Listado 4), las más representadas son cajetes con $40 \%$ de los que $43.8 \%$ tienen paredes rectas divergentes y $31.3 \%$ semiesféricas, seguidos por vasos con $17.5 \%$ y platos con $12.5 \%, y$ finalmente figurillas con $7.5 \%$. Cabe destacar que todas estas formas fueron comunes en el área maya durante el periodo Clásico y las figurillas en particular durante el Clásico Tardío.

Las formas más frecuentes son de tamaño normal, con $85 \%$, mientras que las miniaturas constituyen $15 \%$; estas últimas 
normalmente se han identificado en ofrendas en muchos sitios del área maya y algunas han sido designadas como frascos o perfumeros, que si bien están poco representados entre los materiales aquí catalogados, están en exhibición en el Museo de Palenque (véase Fig. 16) y otras de las miniaturas aquí catalogadas de hecho eran tapas de vasijas con dimensiones normales.

En cuanto a atributos formales específicos, los bordes (véase Listado 5) más representados son: directo redondo, con $32.5 \%$, directo cuadrado, con $15 \%$, y evertido con biselado interno también con $15 \%$; los bordes directo redondo están asociados a cajetes, con $53.8 \%$ y vasos con $30.8 \%$, mientras que de los directos cuadrados $66.7 \%$ corresponden a cajetes y los evertidos con biselado interno se relacionan principalmente a platos, con $50 \%$ y cajetes, con $33.3 \%$. Los cuerpos (véase Listado 6) más comunes son: recto divergente, con $35 \%$, semiesférico con $25 \%$ y recto con curvatura externa, con $15 \%$; los cuerpos rectos divergentes se asocian básicamente a cajetes con $50 \%$, al igual que los semiesféricos con $50 \%$, mientras que los rectos con curvatura externa se relacionan con cajetes, con $50 \%$ y vasos con $50 \%$.

Los fondos más representados (véase Listado 7) son los planos, con $45 \%$, seguidos por cóncavos, con $17.5 \%$ y no determinables también con $17.5 \%$, puesto que había vasijas incompletas; los fondos planos se asocian principalmente a vasos, con $38.9 \%$, cajetes, con $22.2 \%$, y platos, con $16.7 \%$, en tanto que los cóncavos se relacionan básicamente con cajetes, con $71.4 \%$. Dado que el mayor porcentaje de fondos es plano, las bases con mayor frecuencia son las planas, con $57.5 \%$, seguidas por aquéllas cuyas características no pudieron determinarse, con $22.5 \%$ y cóncavas con $12.5 \%$.

Puesto que las jarras únicamente constituyen $5 \%$ del total de formas, $95 \%$ de las vasijas catalogadas carecen de cuello y de hombro, y en lo referente a soportes el $80 \%$ de los objetos carecen de ellos (véase Listado 8). De acuerdo a los comentarios anteriores, puede observarse que las frecuencias más altas se asocian con las formas generales más representadas, es decir cajetes, platos y vasos y, aunque no se ha determinado con precisión cuál es su función, su carácter parece ser más elevado en términos de asociación a estatus social que el de formas netamente utilitarias como jarras y ollas. 
En lo referente a la textura de la pasta, es media en $57.5 \%$ de los casos, no pudo determinarse en el $25 \%$, por tratarse de piezas completas, es fina en $15 \%$ y burda en $2.5 \%$; y en cuanto a su composición, el desgrasante es de cuarzo en $75 \%$ de los objetos y en el resto de los casos no pudo definirse por la misma razón que la textura.

Para el acabado de la superficie, presentan engobe $35 \%$ de los objetos, carecen de él $40 \%$ y cuentan con baño $25 \%$. En cuanto a técnica decorativa no están decorados $80 \%$ de los objetos, presentan decoración al pastillaje $7.5 \%$, que es una técnica asociada a la ornamentación final de figurillas, están pintadas $5 \%$, presentan impresión $5 \%$ e inciso punzonado $2.5 \%$.

Las frecuencias de mayor interés son las referentes a complejo (véase Listado 9), pues el más representado es Murciélagos, con $37.5 \%$, seguido por Motiepa con $17.5 \%$, OtolumMurciélagos con $12.5 \%$ y Balunté Temprano con $10 \%$. Estas frecuencias indican que aun cuando la muestra analizada se restrinja a las piezas almacenadas en la bodega de Palenque, representan el periodo de apogeo del sitio, es decir, el siglo VIII de nuestra era, correspondiente al complejo Murciélagos. El hecho de que el complejo Motiepa, uno de los más tempranos para el sitio, sea el segundo en términos de representatividad se debe a que están en la bodega las vasijas que se encontraron como ofrenda en la tumba más antigua conocida para Palenque, que se localizó en el Templo XVIII-A. 


\section{LISTADO 3}

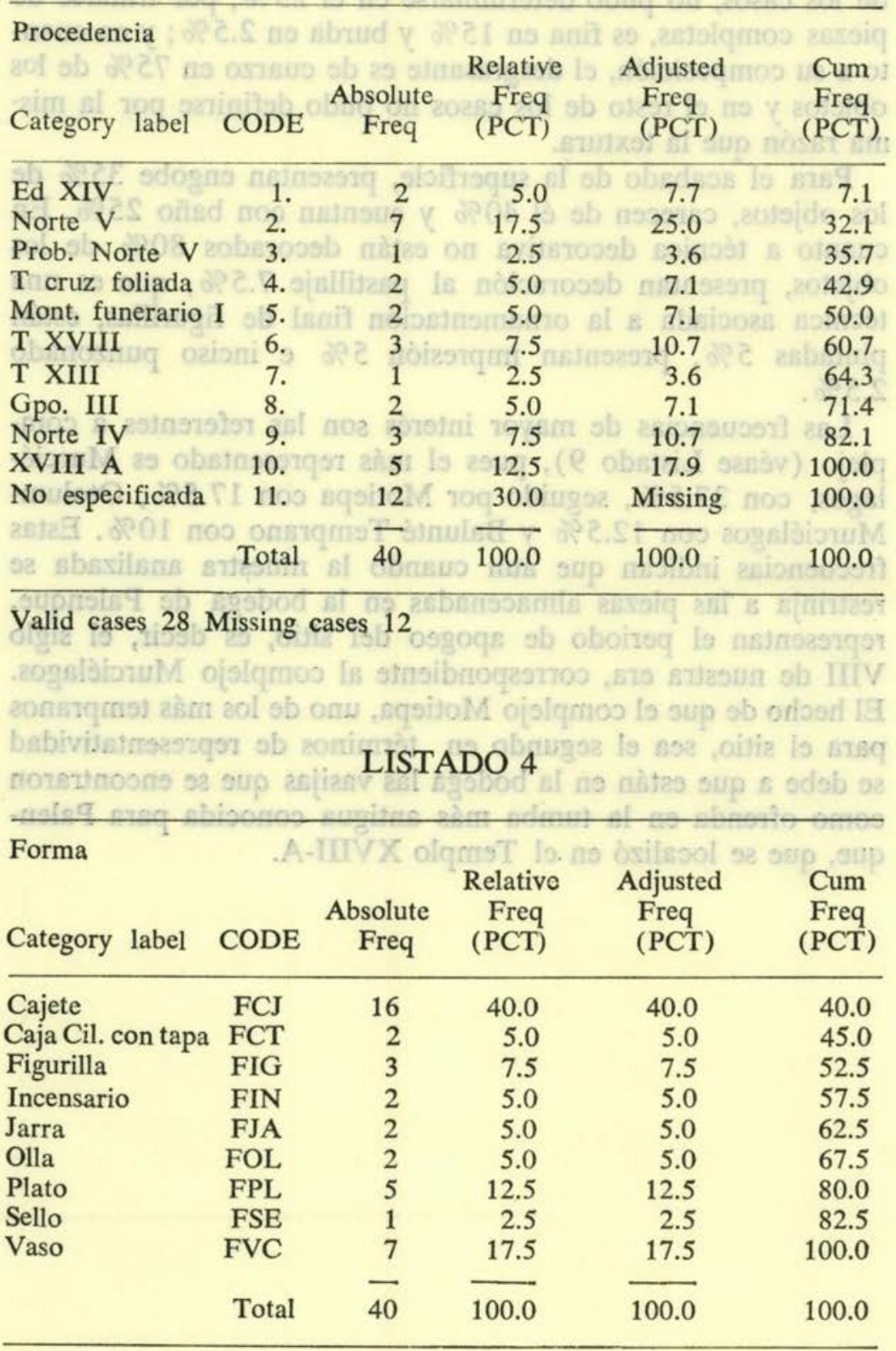

Valid cases 40 Missing cases 0 


\section{LISTADO 5}

\begin{tabular}{lccccc}
\hline Borde & & & & & \\
Relative & $\begin{array}{c}\text { Adjusted } \\
\text { Freq } \\
\text { Freq }\end{array}$ & $\begin{array}{r}\text { Cum } \\
\text { Freq } \\
\text { (PCT) }\end{array}$ \\
\hline Reborde labial & 2. & 2 & 5.0 & 5.9 & 5.9 \\
Directo cuadrado & 3. & 6 & 15.0 & 17.6 & 23.5 \\
Directo redondo & 4. & 13 & 32.5 & 38.2 & 61.8 \\
Red. Lig. evertido & 5. & 2 & 5.0 & 5.9 & 67.6 \\
Biselado Ext. & 6. & 2 & 5.0 & 5.9 & 73.5 \\
Evert enAng. recto & 7. & 1 & 2.5 & 2.9 & 76.5 \\
Invertido aplanado & 9. & 2 & 5.0 & 5.9 & 82.4 \\
Evert con Bis. Int. & 10. & 6 & 15.0 & 17.6 & 100.0 \\
No determinable & 11. & 6 & 15.0 & Missing & 100.0 \\
& Total & 40 & 100.0 & 100.00 & \\
\hline
\end{tabular}

Valid cases 34 Missing cases 6

\section{LISTADO 6}

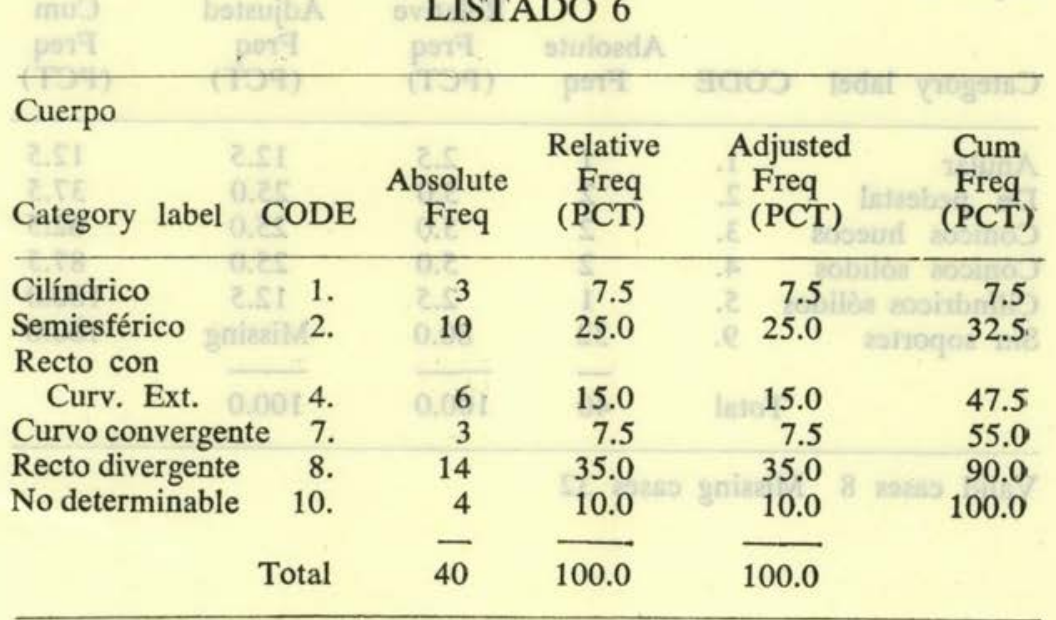

Valid cases 40 Missing cases 0 


\section{LISTADO 7}

\begin{tabular}{|c|c|c|c|c|c|}
\hline $\begin{array}{l}\text { Fondo } \\
\text { Category label }\end{array}$ & CODE & $\begin{array}{l}\text { Absolute } \\
\text { Freq }\end{array}$ & $\begin{array}{c}\text { Relative } \\
\text { Freq } \\
\text { (PCT) }\end{array}$ & $\begin{array}{l}\text { Adjusted } \\
\text { Freq } \\
\text { (PCT) }\end{array}$ & $\begin{array}{c}\text { Cum } \\
\text { Freq } \\
\text { (PCT) }\end{array}$ \\
\hline Plano & 1. & 18 & 45.0 & 54.5 & 54.5 \\
\hline Concavidad cent & tral 2. & 2 & 5.0 & 6.1 & 60.6 \\
\hline Cóncavo & 3. & 7 & 17.5 & 21.2 & 81.8 \\
\hline Convexo & 4. & 6 & 15.0 & 18.2 & 100.0 \\
\hline No determinable & le 5. & 7 & 17.5 & Missing & 100.0 \\
\hline 2.20790 & & - & $\longrightarrow$ & - & Gua $1794=$ \\
\hline+58 & Total & 40 & 100.0 & 100.0 & bistern: \\
\hline
\end{tabular}

Valid cases $33 \quad$ Missing cases 7

\section{LISTADO 8}

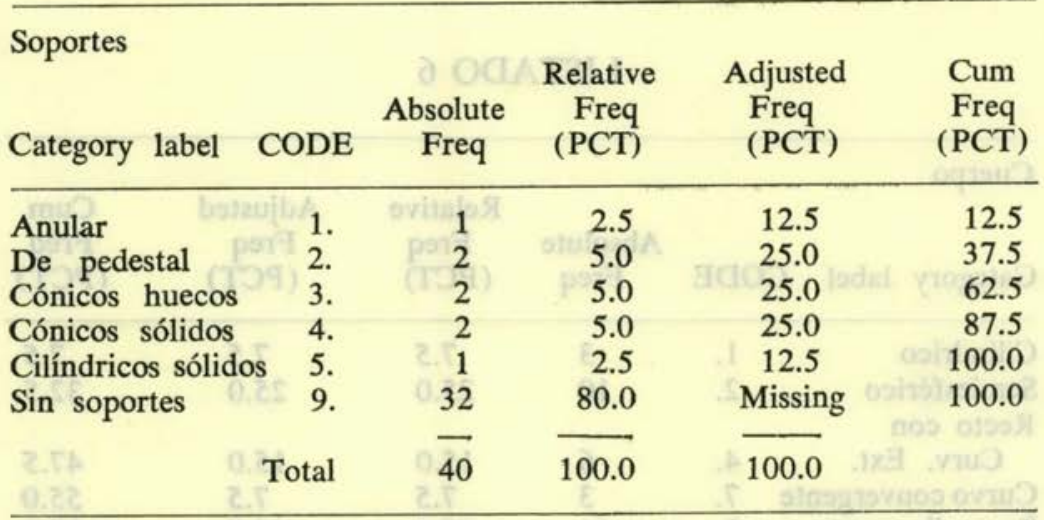

Valid cases 8 Missing cases 32 


\section{LISTADO 9}

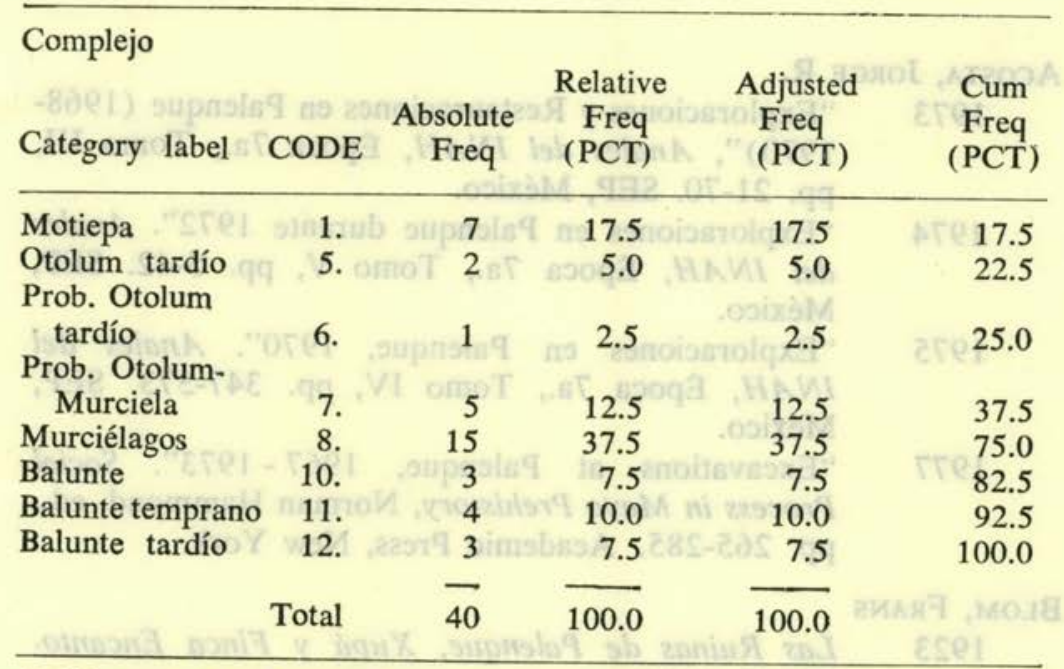

Valid cases 40 Missing cases 0

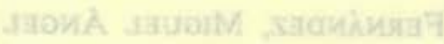

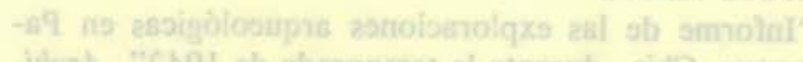

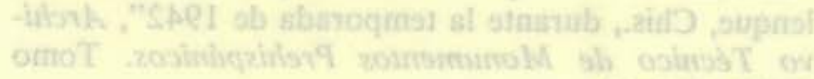




\section{BIBLIOGRAFIA}

ACOSTA, JoRge R.

1973 "Exploraciones y Restauraciones en Palenque (19681970)", Anales del INAH, Época 7a., Tomo III, pp. 21-70. SEP, México.

1974 "Exploraciones en Palenque durante 1972". Anales $\operatorname{del} I N A H$, Epoca 7a., Tomo V, pp. 5-42. SEP, México.

1975 "Exploraciones en Palenque, 1970". Anales del INAH, Época 7a., Tomo IV, pp. 347-373. SEP, México.

1977 "Excavations at Palenque, $1967-1973$ ". Social Pnocess in Maya Prehistory, Norman Hammond, ed., pp. 265-285. Academic Press, New York.

BLOM, Frans

1923 Las Ruinas de Palenque, Xupá y Finca Encanto. INAH, México.

Fernández, Miguel ÁNgel

1943 "Informe de las exploraciones arqueológicas en Palenque, Chis., durante la temporada de 1942", Archivo Técnico de Monumentos Prehispánicos. Tomo XVII, 221-14.

Hernández Reyes, Carlos

1972 "Exploración de Tumbas en Palenque, 1972", Archivo Técnico de Monumentos Prehispánicos. Fol. $311.41(\mathrm{Z} 73-1) / 1$.

Munsell Soil Color Charts

1975 Munsell Color, Macbeth Division of Kollmorgen Corporation, Baltimore, Maryland.

RANDS, ROBERT L.

1965 Pottery of the Greater Palenque Region, Mexico. Progress Report on Investigations conducted in 19641965 by the Research Laboratories of Anthropology, University of North Carolina.

1969 Mayan Ecology and Trade: 1967-1968. Mesoamerican Studies, Research Records. University Museum, Southern Illinois University, Series 69M (2) A Carbondale. 
1973 "The Classic Maya Collapse: Usumacinta Zone and North-western Periphery". The Classic Maya Collapse, T. P. Culbert, ed. University of New Mexico Press. Alburquerque, pp. 165-205.

1974 a "The Ceramic Sequence at Palenque, Chiapas". Mesoamerican Archaelogy, New Approaches. Norman Hammond, ed. pp. 51-75. University of Texas Press, Austin.

1974 b "A Chronological Framework for Palenque". Primera Mesa Redonda de Palenque, Part I, pp. 35-39. Robert Louis Stevenson Scholl, Pebble Beach.

RANDS, R. L. \& B. C. RANDS

1957 "The Ceramic Position of Palenque, Chiapas". American Antiquity, vol. 23, no. 2, pp. 140-150. Salt Lake City.

1959 "The Incensario Complex at Palenque, Chiapas". American Antiquity, vol. 25, pp. 225-236. Salt Lake City.

1965 "Pottery Figurines of the Maya Lowlands". Handbook of Middle American Indians, vol. 2, Archaeology of Southern Mesoamerica. R. Wauchope \& G. R. Willey, ed. pp. 535-560. University of Texas Press, Austin.

1967 "Cerámica de la región de Palenque". Estudios de Cultura Maya. 6:111-147. UNAM. México.

RANDS, R. L. \& R. L. BISHOP

1975 Aspects of Ceramic Paste Composition and Trade in the Palenque Region, Chiapas and Tabasco. Progress Report to the Instituto Nacional de Antropología e Historia, México. University Museum, Southern Illinois University, Carbondale.

RaNDS, R. L., R. L. Bishop \& G. HaRbottlle

1978 "Thematic and Compositional Variation in Palenque-Region Incensarios". Tercera Mesa Redonda de Palenque, vol. IV, pp. 19130. Pre-Columbian Art Research, Heral Printer, Montrey, California.

Ruz Lhuillier, Alberto

1950 "Exploraciones Arqueológicas en Palenque, Chis., durante la temporada de 1950". Archivo Técnico de Monumentos Prehispánicos. Tomo XXI, 229-1.

1952 "Exploraciones en Palenque, 1952". Archivo Técnico de Monumentos Prehispánicos. Tomo XXIII, 232-1. 
1953 "Exploraciones Arqueológicas en Palenque, 1953". Archivo Técnico de Monumentos Prehispánicos. Tomo XXIV, 234-1.

1954 "Informe de las exploraciones arqueológicas efectuadas en Palenque, de mayo 10 a agosto 22 de 1954". Archivo Técnico de Monumentos Prehispánicos. Tomo XXIV, 235-2.

1957 "Exploraciones Arqueológicas en Palenque: 1955". Archivo Técnico de Monumentos Prehispánicos. Tomo XXV, 237-1.

1958 a "Exploraciones Arqueológicas en Palenque, Chis., llevadas a cabo de agosto 13 a noviembre 4 de 1956". Archivo Técnico de Monumentos Prehispánicos. Tomo XXV, 238-2.

1958 b "Exploraciones Arqueológicas en Palenque. 1954". Anales del INAH, vol. 10, no. 39, pp. 117-184. México.

1959 "Exploraciones Arqueológicas en Palenque: 1957". Archivo Técnico de Monumentos Prehispánicos. Tomo XXVI, 240-1.

1973 El Templo de las Inscripciones, Palenque. INAH, Colección Científica, no. 7, México.

1978 Palenque. Official Guide. INAH, México.

SAÉnZ, CÉsAR A.

1979 "Exploraciones y restauraciones en Palenque, 1979". Archivo Técnico de Monumentos Prehispánicos. Fol. C/311.43 (3) /22-35.

Schele, Linda \& Peter Mathews

1979 The Bodega of Palenque, Chiapas, México, Dumbarton Oaks, Trustees for Harvard University, Washington, D. C.

SMITH, R. E. \& J. C. GiFForD

1965 "Pottery of the Maya Lowlands". Handbook of Middle American Indians, vol. 2. R. Wauchope y G. R. Willey (eds.). University of Texas Press, Austin.

WiLley, GoRdon R.

1978 Artifacts: Excavations at Seibal. Memoirs of the Peabody Museum of Archaeology and Ethnology, Harvard University, vo!. 14, Part. 1. pp. 1-138. Cambridge. 
Zavala, Lauro José

1949 "Exploraciones Arqueológicas en Palenque, Chis., Sección de Tumbas". Archivo Técnico de Monumentos Prehispánicos. Tomo XX, 228-1.

1950 "Informe de los trabajos en Palenque, Chis. Temporada de 1950". Archivo Técnico de Monumentos Prehispánicos. Tomo XXII, 230-1.

1951-1976 "Documentación sobre los trabajos de exploraciones e investigaciones en las zonas arqueológicas de la República Mexicana por el Dr. Robert L. Rands". Archivo Técnico de Monumentos Prehispánicos. Fol. B/311.42R/21-1. 